\title{
Saúde Coletiva, Meio \\ Ambiente e Sociedade
}

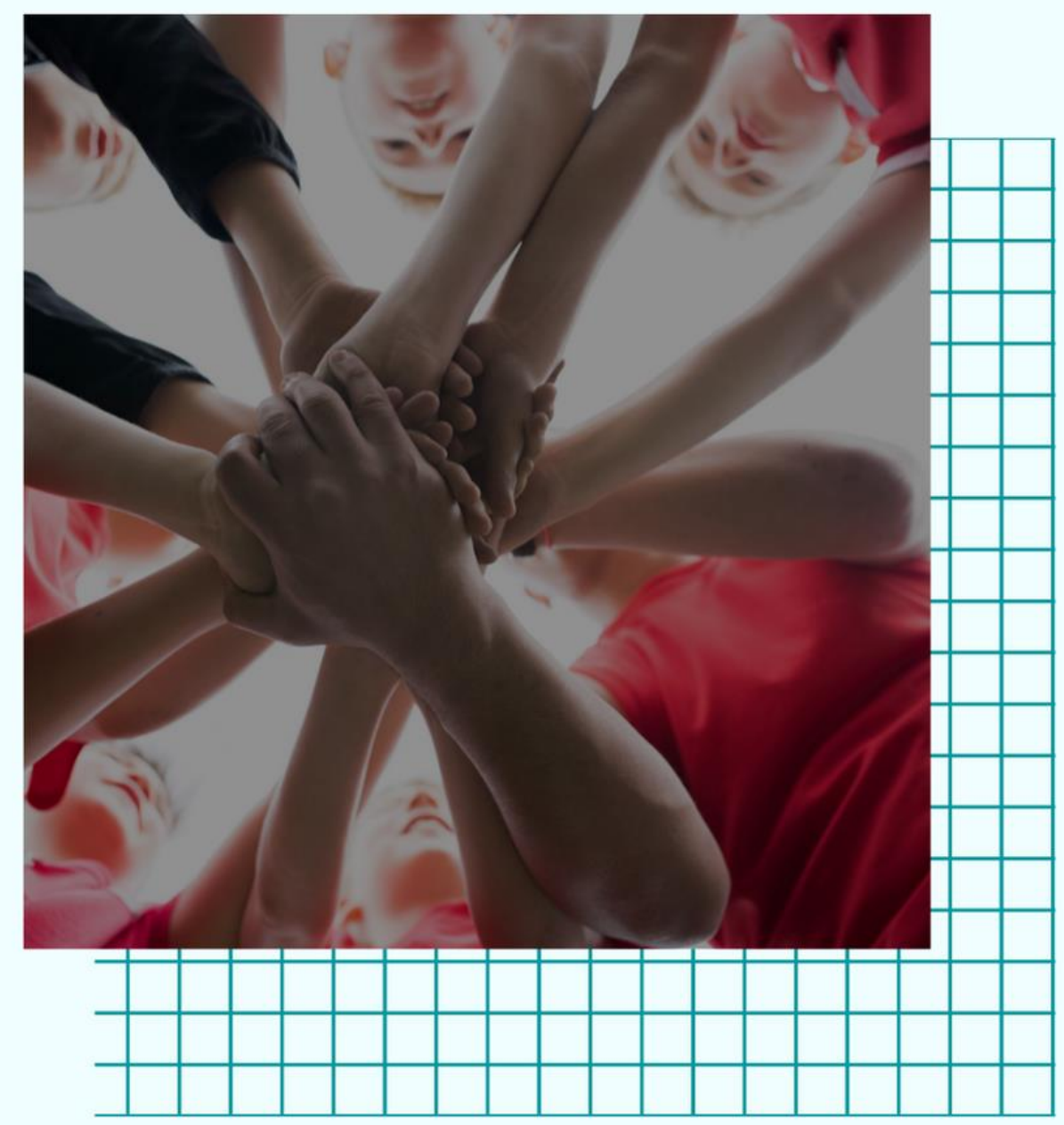

\section{Organizadores}

Lílian Natália Ferreira de Lima

Karla Vanessa Morais Lima

Francisco Alves Lima Júnior

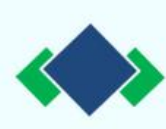

Editora Poisson

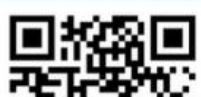

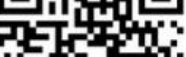

(1)

口脿和; 


\author{
Organizadores \\ Lílian Natália Ferreira de Lima \\ Karla Vanessa Morais Lima \\ Francisco Alves Lima Júnior
}

\title{
Saúde Coletiva, Meio Ambiente e Sociedade
}

1a Edição

Belo Horizonte

Poisson

2021 


\section{Editor Chefe: Dr. Darly Fernando Andrade}

\section{Conselho Editorial}

Dr. Antônio Artur de Souza - Universidade Federal de Minas Gerais

Ms. Davilson Eduardo Andrade

Dra. Elizângela de Jesus Oliveira - Universidade Federal do Amazonas

Msc. Fabiane dos Santos

Dr. José Eduardo Ferreira Lopes - Universidade Federal de Uberlândia

Dr. Otaviano Francisco Neves - Pontifícia Universidade Católica de Minas Gerais

Dr. Luiz Cláudio de Lima - Universidade FUMEC

Dr. Nelson Ferreira Filho - Faculdades Kennedy

Ms. Valdiney Alves de Oliveira - Universidade Federal de Uberlândia

Dados Internacionais de Catalogação na Publicação (CIP)

\begin{tabular}{l} 
S255 Saúde Coletiva, Meio Ambiente e Sociedade/ \\
Organização: Lílian Natália Ferreira de Lima, \\
Karla Vanessa Morais Lima, Francisco Alves Lima \\
Júnior/ Editora Poisson - Belo Horizonte - MG: \\
Poisson, 2021 \\
Formato: PDF \\
ISBN: 978-65-5866-136-8 \\
DoI: 10.36229/978-65-5866-136-8 \\
Modo de acesso: World Wide Web \\
Inclui bibliografia \\
1.Saúde 2. Enfermagem 3. Meio Ambiente I. LIMA, \\
Lílian Natália Ferreira de II. LIMA, Karla Vanessa \\
Morais III. JúnIoR, Francisco Alves Lima IV. Título \\
\hline Sônia Márcia Soares de Moura - CRB 6/1896
\end{tabular}

O conteúdo deste livro está licenciado sob a Licença de Atribuição Creative Commons 4.0.

Com ela é permitido compartilhar o livro, devendo ser dado o devido crédito, não podendo ser utilizado para fins comerciais e nem ser alterada.

O conteúdo dos artigos e seus dados em sua forma, correção e confiabilidade são de responsabilidade exclusiva dos seus respectivos autores.

www.poisson.com.br

contato@poisson.com.br 


\section{ORGANIZADORES}

\section{Lilian Natália Ferreira de Lima}

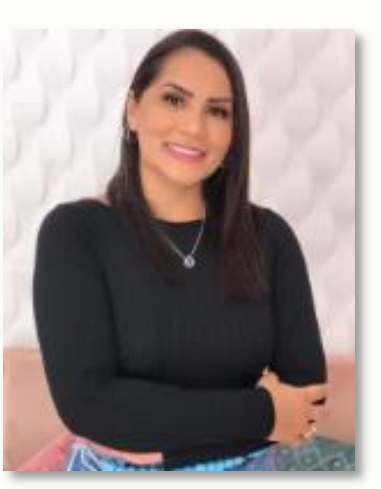

Doutoranda no programa de Pós-Graduação em Biologia de Agentes Infecciosos e parasitários na Universidade estadual do Pará (UFPA) Mestre em Ensino de Ciências Ambientais pelo Programa de Pós-Graduação em Ciências Ambientais na Faculdade de Geociências da Universidade Federal do Pará(UFPA). Especialista em docência do ensino Superior pela Faculdade João Calvino(FJC). Especialista em Diversidade de Gênero na Escola pela Universidade Federal do Tocantins(UFT). Graduada em Ciências Naturais-Biologia pela Universidade Estadual do Pará (UEPA). Professora na Universidade Estadual do Tocantins. Revisora da Revista Acervo Saúde. Líder do grupo de pesquisa Doenças infecciosas e Negligenciadas (DIN/UNITINS). Vice-coordenadora do Comitê de ética e pesquisa da Unitins(CEP).

\section{Karla Vanessa Morais Lima}

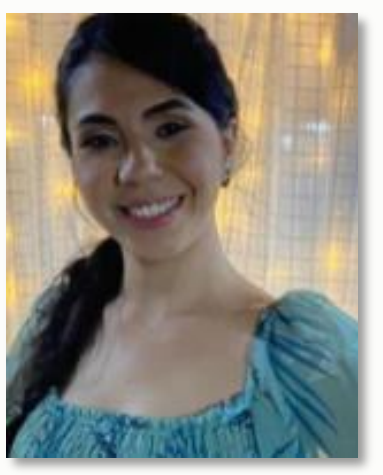

Enfermeira pela Universidade Estadual do Maranhão. Especialista em Unidade de Terapia Intensiva-INESPO; especialista em Gestão em Saúde pela UFMA; especialista em Ativação do processo de mudança na formação superior de profissionais da saúde pela Escola Nacional de Saúde Pública Sérgio Arouca(ESNP- FIOCRUZ); Mestranda do programa de pós-graduação em Biologia Microbiana-UNICEUMA. Possui experiência nas áreas de saúde do adulto (UTI e clínica médica), saúde da criança e adolescente, educação em saúde/ permanente. Atualmente é professora substituta do curso de Medicina da Universidade Estadual da Região Tocantina, na área de laboratório de habilidades clínicas. Consultora independente nas áreas de gestão e educação em saúde.

\section{Francisco Alves Lima Júnior}

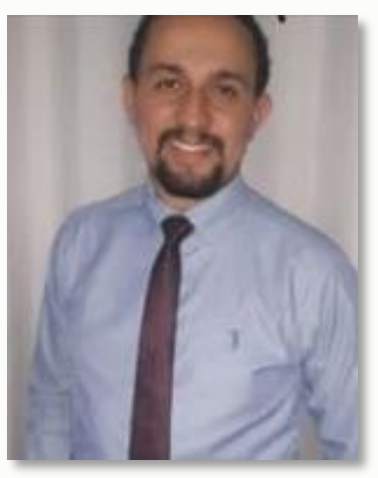

Enfermeiro, formado pela Universidade Estadual MaranhãoUEMA. Especialista em Enf ermagem em Terapia Intensiva INESPO, Enfermagem Trabalho - FACIBRA e Ativação de Processo de Mudança na Formação Superior de Profissionais de Saúde pela Escola Nacional de Saúde Pública, Fundação Oswaldo Cruz ENSPFIOCRUZ. Fez mestrado pelo programa de Cirurgia e Pesquisa Experimental na Universidade do Estado do Pará - UEPA e cursa o Doutorado no programa de pós-graduação em Enfermagem pela Faculdade de Medicina de Botucatu, Universidade do Estado de São Paulo FMB-UNESP. Atualmente é docente na Universidade Ceuma, Campus Imperatriz, nos cursos de Enfermagem e Medicina. Tem sua linha de pesquisa voltada para o desenvolvimento de tecnologia para gestão em saúde e Enfermagem em situações críticas. 


\section{PREFÁCIO}

Este livro traz contribuição original e significativa por meio de diversas abordagens relacionadas as ciências da saúde e da educação, em especial para a área de ensino de graduação e saúde pública, visto que se destaca não só pela qualidade dos artigos, mas pela pertinência da escolha do tema e por reunir recortes dos diferentes aspectos da educação e da saúde, uma vez que tanto a questão da metodologia de ensino, quanto o meio ambiente e social interferem tal como na formação dos profissionais, bem como no processo de promoção, prevenção e recuperação da saúde, respectivamente. Dessa forma, a presente coletânea traz temática de suma importância da compreensão da saúde pública no processo de assistência à saúde da população. Portanto, o livro estar disponível em 8 capítulos. No capítulo 1 é abordado as metodologias mais utilizados no ensino em graduação de enfermagem, uma vez que, por se tratar de estudo bibliográfica utilizasse fontes de artigos periódicos científicos publicados no período de janeiro de 2017 a setembro de 2020. Sendo assim, o capítulo 2 apresenta a avaliação dos parâmetros físico-químicos da água de dois poços do assentamento Palmares, no município de Araguatins no estado do Tocantins, comparando-os com os valores da Portaria de consolidação ${ }^{\circ} 5 / 2017$, e além disso, as coletas das amostras ocorreram em 5 dias consecutivos, compreendendo o período de 16 a 20 de outubro de 2017 com a utilização de termômetro, turbidímetro, pHmetro e sonda multiparamétrica. Dessa maneira, no capitulo 3 aborda o perfil sociodemográfico, hábitos de higiene e consumo dos manipuladores de alimentos das escolas públicas da área urbana do município de Augustinópolis-TO no período de 2020, e além do mais, por tratar de estudo de campo foi desenvolvido mediante aprovação do Comitê de Ética em Pesquisa da Universidade Estadual do Tocantins sob no CAAE 15025119.8.0000.8023 e o parecer 3.503.572, o instrumento de coleta de dados foi através da aplicação de formulários socioeconômico. Assim, o capítulo 4 apresenta a relação tanto entre o meio ambiente e os índices de malária, quanto o conhecimento dos pacientes infectados pela patologia no ano de 2017, no centro de Araguatins, Tocantins, visto que os dados primários foram coletados por meio do SIVEP- Malária, fornecidos pela coordenação de endemias do município e posteriormente por meio de formulário semiestruturado contendo 20 questões abertas e fechadas. Nessa pespectiva, os capítulos 5 e 6 abordam os fatores que interferem no processo de adesão ao tratamento da HAS na população adulta do Brasil no intervalo de 2015 a 2021 e o perfil da população adulta do Brasil acometida pela hipertensão arterial 
sistêmica nos anos de 2016 a 2021, respectivamente, tais capítulos tratam de pesquisa bibliográfica de abordagem qualitativa com a utilização do método revisão integrativa. No capítulo 7 aborda o conhecimento dos enfermeiros sobre os tipos de violências contra a mulher e as políticas públicas existentes especificas do setor saúde em relação a violência, o estudo foi realizado no município de Araguatins estado do Tocantins no período de 2020, visto que a realização do estudo foi na nas Unidades Básicas de Saúde por meio da aplicação de questionário aos profissionais enfermeiros. Portanto, o capítulo 8 trata-se da verificação das ações de promoção e prevenção a violência contra a mulher, as dificuldades enfrentadas durante $\mathrm{o}$ atendimento, a realização $\mathrm{e}$ conhecimento sobre as notificações compulsórias e a realização de educação em saúde frente à violência contra a mulher, no município de Araguatins, no Estado do Tocantins, além de que a pesquisa foi realizada nas Unidades Básicas de Saúde no município de Araguatins e o instrumento de coleta de dados foi um questionário para os profissionais de enfermagem da UBS. Por fim, verifica-se que, espera-se que este livro possa contribuir positivamente, trazendo reflexões sobre as novas formas de abordar e integrar os pacientes dentro da Saúde Pública. 


\section{SUIÁRIO}

Capítulo 1: Educação em saúde: Ações de promoção e prevenção frente à violência contra a mulher

Thays Gouveia Miranda dos Reis, Lilian Natália Ferreira de Lima, Luysa dos Santos Sanches, Luciana do Socorro Lima da Silva, Onayane dos Santos Oliveira, Nayara Sousa de Lima, Maria Adenilda da Silva, Halan Heverton dos Santos Nobre, Iracema Sousa Santos Mourão, Raquel Machado Borges

DOI: $10.36229 / 978-65-5866-136-8 . C A P .01$

Capítulo 2: Caracterização do perfil de pacientes adultos acometidos pela hipertensão arterial sistêmica no Brasil: Uma revisão integrativa 19

Andressa Flores Mendes, Lílian Natália Ferreira de Lima, Jonathan Fernandes da Silva, Cristina Limeira Leite, Cristiana Maria de Araújo Soares Gomes, Patrícia dos Santos Silva Queiroz, Iracema Sousa Santos Mourão, Érika Ferreira Tourinho, Francisco Alves Lima Junior, Dennis Gonçalves Novais

DOI: $10.36229 / 978-65-5866-136-8 . C A P .02$

Capítulo 3: Metodologias de ensino em graduação de enfermagem 33

Dhonnel Oliveira da Silva, Catilena Silva Pereira, Rafael Oliveira Chaves, Silvana Nascimento Soares, Edson Ferreira de Araújo, Iracema Sousa Santos Mourão, Renilda da Silva Soares, Francisco Alves Lima Junior, Karla Vanessa Morais Lima, Cristiana Maria de Araújo Soares Gomes

DOI: 10.36229/978-65-5866-136-8.CAP.03

Capítulo 4: Avaliação da potabilidade da água de poços do assentamento Palmares, Araguatins-To 41

Igor Garcia Moura, Lilian Natalia Ferreira de Lima, Cléber Silva e Silva, Ênio Rocha Santos, Ricardo Henrique Paes Barreto Peixoto, Antônio Silva Machado, Marcia Guelma Santos Belfort, Herculano Rodrigues Silva, Wilma Helena da Rocha Falcão, Patrick Assunção Mourão

DOI: $10.36229 / 978-65-5866-136-8 . C A P .04$

Capítulo 5: Malária x meio ambiente: Percepção dos pacientes infectados na região central do município de Araguatins, Tocantins.

Tárcila Cristina Cunha Cavalcante, Lílian Natália Ferreira de Lima, Dennis Gonçalves Novais, Marcia Guelma Santos Belfort, Karla Vanessa Morais Lima, Antônio Silva Machado, Francisco Alves Lima Junior, Jonathan Fernandes da Silva, Cristina Limeira Leite, Dhonnel Oliveira da Silva

DOI: 10.36229/978-65-5866-136-8.CAP.05 
Capítulo 6: Adesão ao tratamento de pacientes adultos acometidos pela hipertensão arterial sistêmica no Brasil: Uma revisão integrativa

Andressa Flores Mendes, Lilian Natalia Ferreira de Lima, Jonathan Fernandes da Silva, Onayane dos Santos Oliveira, Francisco Alves Lima Junior, Katiane Gomes Gonçalves, Paula Cristina de Sousa Vieira, Renata de Sá Ribeiro, Érika Ferreira Tourinho, Artur de Souza Veras

DOI: $10.36229 / 978-65-5866-136-8 . C A P .06$

Capítulo 7: 0 perfil sociodemográfico, hábitos de higiene e consumo dos manipuladores de alimentos das escolas públicas do município de Augustinópolis-To 69

Géssica Queiroz da Silva, Lílian Natália Ferreira de Lima, Luysa dos Santos Sanches, Antônio Silva Machado, Marcia Guelma Santos Belfort, Dennis Gonçalves Novais, Ricardo Henrique Paes Barreto Peixoto, Katiane Gomes Gonçalves, Paula Cristina de Sousa Vieira, Nayara Sousa de Lima

DOI: $10.36229 / 978-65-5866-136-8 . C A P .07$

Capítulo 8: 0 conhecimento dos enfermeiros sobre as políticas públicas existentes especificas do setor saúde em relação a violência contra a mulher

Thays Gouveia Miranda Dos Reis, Lilian Natália Ferreira de Lima, Luysa dos Santos Sanches, Luciana do Socorro Lima da Silva, Artur de Souza Veras, Raquel Machado Borges, Halan Heverton dos Santos Nobre, Patrícia dos Santos Silva Queiroz, Dennis Gonçalves Novais, Cristiana Maria de Araújo Soares Gomes

DOI: $10.36229 / 978-65-5866-136-8 . C A P .08$ 


\section{Capítulo 1}

\section{Educação em saúde: Ações de promoção e prevenção frente à violência contra a mulher}

Thays Gouveia Miranda Dos Reis

Lilian Natália Ferreira de Lima

Luysa dos Santos Sanches

Luciana do Socorro Lima da Silva

Onayane dos Santos Oliveira
Nayara Sousa de Lima

Maria Adenilda da Silva

Halan Heverton dos Santos Nobre

Iracema Sousa Santos Mourão

Raquel Machado Borges

Resumo: Verificar as ações de promoção e prevenção a violência contra a mulher, as dificuldades enfrentadas durante o atendimento, a realização e conhecimento sobre as notificações compulsórias e a realização de educação em saúde frente à violência contra a mulher. Pesquisa de caráter exploratório e de abordagem qualitativa e o instrumento de coleta de dados um questionário, aplicado as 09 enfermeiras que atuam nas UBS do município de Araguatins, no Estado do Tocantins. Os participantes mostraram conhecer todas as redes de apoio necessárias para assistência e encaminhamento, pois é a base para desenvolver ações contra a violência, além do mais, os dados mostraram as dificuldades na abordagem da vítima e isso e a falta de planejamento por parte da gestão, e em contrapartida as participantes relataram conhecer a importância das notificações e, para finalizar, no que diz respeito a educação permanente voltadas pra violência contra a mulher, obteve-se o resultado esperado nas hipóteses desta pesquisa, quando apenas uma das participantes recebeu treinamento.Por fim, é fundamental que todos os profissionais sejam capacitados para a identificação da violência, assim como para o manejo dessas situações, desenvolvendo melhor relação com as vítimas e um protocolo de atendimento multiprofissional eficaz.

Palavras-chave: Violência Contra a Mulher, Assistência a Saúde, Educação em Saúde. 


\section{INTRODUÇÃO}

Dessa maneira, de acordo com as Nações Unidas definem a violência contra as mulheres sendo como qualquer ato de violência de gênero que resulte ou possa resultar em danos ou sofrimentos físicos, sexuais ou mentais para as mulheres, inclusive ameaças, coação ou privação arbitrária de liberdade, visto que pode ser em vida pública ou privada. Sendo assim, a violência doméstica e familiar contra a mulher não é apenas a violência física, mas também inclui a psicológica, moral, sexual e patrimonial, no âmbito da unidade doméstica, da família e em qualquer relação íntima de afeto, em que o agressor conviva ou tenha convivido com a agredida, pois esses tipos de violência estar presente na Lei Maria da Penha de n 11.340 de 07 de Agosto de 2006.

Dessa maneira, de acordo com o relatório do Anuário Brasileiro de Segurança Pública 2019, mostra que os feminicídios correspondem a 29,6\% dos homicídios dolosos de mulheres em 2018, e além do que foi exposto anteriormente, foram registrados 1.151 casos em 2017 e 1.206 em 2018 e em comparação entre o ano de 2017 e 2018 observase um crescimento de $4 \%$ nos números absolutos, e além disso, a violência sexual, da qual $81,8 \%$ das vítimas são do sexo feminino, cresceu 4,1\%. Sendo assim, a violência contra as mulheres fere os direitos humanos, afetando-as psicologicamente, fisicamente e violando seus direitos. Assim, com o intuito de reduzir a violência contra a mulher e de suma importância promover ações de promoção e prevenção a violência, e além disso, realizar educação em saúde sobre a temática e ter conhecimento sobre a notificação compulsória. Nesse sentido, o enfermeiro é responsável por coordenar as ações de prevenção, e além do mais, é o primeiro a atender as vítimas e deve prestar o cuidado e assistência integral e individualizada, visto que é um dos profissionais com maior presença nos cenários do cuidar por ser um dos primeiros a entrar em contato com as vítimas de violência, porém os enfermeiros encontram-se pouco preparadas para a prestação da assistência para as vítimas, pois tem a falta de capacitação profissional que traz como consequência a dificuldade de identificar a violência vivida por essa mulher ( PETRICIO, 2018; SERAFIM VVD, et al. (2018).

Portanto, o presente estudo buscou responder a seguinte problemática: os profissionais estão realizando as ações de promoção e prevenção a violência, estão capacitados para enfrentar as dificuldades, tem conhecimento sobre as notificações compulsórias e se estão fazendo educação em saúde sobre o assunto de violência contra a mulher. Nesse aspecto, o objetivo desse artigo e verificar as ações de promoção e 
prevenção a violência contra a mulher, as dificuldades enfrentadas durante o atendimento, a realização e conhecimento sobre as notificações compulsórias e a realização de educação em saúde frente à violência contra a mulher.

\section{MÉTODOS}

Dessa maneira, o método de estudo estar de acordo com uma pesquisa de cunho exploratória, de abordagem qualitativa. Assim, de acordo com Gil (1999) afirma que a pesquisa exploratória é desenvolvida no sentido de proporcionar uma visão geral acerca de determinado fato, visto que, consiste no aprofundamento de conceitos preliminares sobre determinada temática não contemplada de modo satisfatório anteriormente, sendo assim, contribui para o esclarecimento de questões superficialmente abordadas sobre o tema.

Nessa perspectiva, a pesquisa foi realizada nas Unidades Básicas de Saúde no município de Araguatins, no estado do Tocantins, Brasil e a população estudada foram os profissionais de enfermagem das Unidades Básicas de Saúde da Família - UBS do município de Araguatins - T0, visto que foi realizada a busca ativa de 17 profissionais de enfermagem, que se encaixaram nos critérios de inclusão desta pesquisa, por meio da aplicação de um questionário, mas das 17 enfermeiras atuantes no município no momento da pesquisa apenas 09 enfermeiras aceitaram participar do estudo. Sendo assim, os critérios de seleção da pesquisa estar de acordo com o critério de inclusão que seria: aceitar participar do estudo; atuar nas unidades de Estratégia Saúde da Família do município de Araguatins; e estar no desempenho das atividades profissionais durante a coleta de dados, e além disso, o critério de exclusão estar bom base dos profissionais de férias e/ou com licença médica; e os profissionais que não aceitarem participar da pesquisa.

Dessa forma, os procedimentos foram adotados o ciclo de pesquisa de Minayo (1994), que se baseia em três momentos: fase exploratória da pesquisa, trabalho de campo e tratamento do material. Nesse aspecto, na análise o pesquisador teve como intuito de organizar e sumariar os dados de tal forma que possibilitem o fornecimento de respostas ao problema proposto para investigação, visto que, durante a interpretação procurou-se o sentido mais amplo das respostas, para que assim, possa ser feito mediante sua ligação a outros conhecimentos anteriormente obtidos (GIL, 1999, p. 168 
Portanto, verifica-se que, a pesquisa respeita a resolução 466/12 onde foi instituída a Comissão Nacional de Ética em Pesquisa (CONEP) que é uma comissão do Conselho Nacional de Saúde (CNS), criada com a função de implementar normas e diretrizes regulamentadoras de pesquisas envolvendo seres humanos. Dessa maneira, a resolução propõe que toda pesquisa envolvendo seres humanos direta ou indiretamente deverá ser submetida à apreciação de um Comitê de Ética em Pesquisa. Nesse sentido, foi utilizado o Termo de Consentimento Livre e Esclarecido (TCLE) que é um documento público específico para cada pesquisa e a responsabilidade do pesquisador respeitar e manter a ética em todo o desenvolvimento do trabalho, importante ressaltar que todas as informações pessoais foram mantidas em segredo, respeitando as participantes o máximo para que nenhum dos envolvidos na pesquisa sofresse qualquer tipo de dano. Por fim, o presente estudo foi realizado mediante o parecer favorável do Comitê de Ética em Pesquisa da Universidade Estadual do Tocantins, sob parecer número 4.000.003, na data 30/04/2020, a visto que, respeitando a resolução 466/12 que incorpora, sob a ótica do indivíduo e das coletividades, referenciais da bioética, como, autonomia, não maleficência, beneficência, justiça e equidade, dentre outros, e visa a assegurar os direitos e deveres que dizem respeito aos participantes da pesquisa.

\section{RESULTADOS E DISCUSSÃO}

Dessa forma, os resultados obtidos no estudo serão subdivididos de acordo com os achados do questionário e neste tópico será trabalhado os seguintes achados: ações de promoção e prevenção a violência contra a mulher, dificuldades enfrentadas durante o atendimento, a realização e conhecimento sobre as notificações compulsórias e a realização de educação em saúde frente à violência contra a mulher. Sendo assim, o primeiro tópico do resultado e discussões centra-se nas ações de promoção e prevenção a violência contra a mulher, pois cabe ao enfermeiro ter a didática necessária para o planejamento do cuidado dessas mulheres e reconhecer a necessidade de envolver a rede de atenção do município, orientando sobre a rede de apoio tanto jurídica quanto assistencial no quesito físico, emocional e social (XAVIER e SILVA, 2019), a fim de compreender o conhecimento das enfermeiras foi questionado sobre quais as redes de apoio disponíveis para o atendimento das mulheres no município estudado, obtendo os seguintes resultados: 
E3 - “(...) os mais procurados são o CREAS e a assistência social”.

E8 - “(...) Delegacia de atendimento à mulher, defensoria pública e os serviços de saúde geral”.

E6 - “(..) CREAS, polícia civil”.

Nesse sentido, de acordo com o estudo de Amarijo et al. (2020) apresenta dados semelhantes aos encontrado na presente pesquisa, visto que as participantes mostraram conhecer todas as redes de apoio necessárias para assistência e encaminhamento. Sendo assim, além de discorrer sobre a importância do NASF, CRAS e CREAS, o NASF é um programa onde deve ser encontrado assistência multiprofissional e intersetorial, pois é uma extensão das unidades básicas, onde se encontra diversas especialidades medicas, o CRAS e CREAS são programas de assistência social e psicológica, onde podem ajudar a vítima no acompanhamento emocional.

No segundo tópico, conforme os achados do questionário, foi abordado as dificuldades encontradas pelas enfermeiras na assistência prestada as pacientes que vivem em situação de violência. Assim, em resposta à pergunta "Na sua opinião, que dificuldades você encontra para atender a mulheres vítimas de violência? ", podemos destacar as seguintes falas:

E3 - "A dificuldade maior encontrada nessas mulheres é a resistência em falar sobre a violência, principalmente se for violência física e sexual. Pois elas ficam com medo do parceiro, pois elas se sentem ameaçadas pelos os mesmos".

E5 - "A dificuldade da comunicação. Devemos ter condutas para saber qual a situação de violência, que a pessoa está passando. Muitas vezes a própria mulher não quer falar o que aconteceu. Acionamos se necessário, assistente social, psicólogos ou até mesmo polícia".

Desse modo, nas respostas obtidas pode notar na fala da E3 e E5 a prevalência no que se refere a resistência da mulher relatar violência para as profissionais. A vista disso, já para a participante E6 e E8 a maior dificuldade encontrada é após elas relatarem a violência e no acompanhamento. 
E6 - "A maior dificuldade encontrada por mim é que por muitas das vezes as mulheres relatam a violência, porém a mesma dificulta o acompanhamento por parte das equipes de atenção básica e do serviço de apoio CREAS".

E8 - "Uma das grandes dificuldades é que a maioria dessas mulheres que sofre algum tipo de violência doméstica não busca as unidades de saúde por medo e quando procura atendimentos nas UBS se negam a admitir que passam por situação de violência".

E9 - "[...] muitas vezes a mulher omite informações ou diz que não era ela".

Nesse sentido, os estudos mais antigos como o de Lopes (2005) e Saliba et al. (2007), e estudos mais recentes como por exemplo realizado por Serafim et al. (2019) evidenciam dificuldades encontradas no atendimento como: falta de treinamento, atenção a causa e apoio da instituição, pois quando ela fala a conduta do profissional e se atentar em identificar qual a violência é vivida por essa mulher. Sendo assim, tal identificação é um problema para os profissionais, pois conforma o estudo de Aquino e Passos (2018) afirma em sua pesquisa que 09 das participantes referiram ter dificuldades na abordagem da vítima, e relacionaram isso ao processo de capacitação e a falta de planejamento por parte da gestão.

Dessa forma, no terceiro tópico que será abordado de acordo com os achados do questionário é a importante de ter conhecimento e pôr em prática o fortalecimento de políticas públicas, que recebe mais atenção através dos indicadores e notificações. Posto isso, as participantes relataram conhecer da importância das notificações nesses casos.

E3 - "Sim, todas devem ser notificadas. A violência sexual; A violência física; A violência psicológica; A violência doméstica".

E4 - "Sim. Em situações que causem danos físico, psicológico, sexual, conforme a ficha de notificação do ministério da Saúde".

E6 - "Sim. Notifica-se em casos de: Sexual; Violência a pessoa idosa, criança; Mulheres, pessoas com deficiência; Violência Doméstica".

E9 - "Sim! Deve ser notificado todos os casos em que houver indícios ou confirmação de violência contra a mulher".

A notificação de qualquer tipo de agravo ou violência é obrigatória é a Lei no 10.778/2003 estabelece e institui a notificação da violência contra a mulher. Desse 
modo, o ministério da saúde é responsável por coordenar e regulamentação das notificações em todo o território brasileiro (BRASIL, 2008). Sendo assim, ao procurar pela temática "realização de notificação", a maioria dos artigos encontrados referem que seus participantes não conhecem, nunca receberam instruções de como preencher, não tem as fichas no local de trabalho e diversas situações do gênero (CRUZ et al., 2019; PENNA et al., 2017; SILVA et al., 2017;). Portanto, no presente estudo como observado na fala das participantes, $100 \%$ das profissionais questionadas referiram conhecer as notificações, efetuar ou receber notificações do hospital e fazer a investigação, visto que é notório que elas sabem da importância e necessidade de executar o preenchimento da ficha, quando em diversos momentos da pesquisa mesmo sem serem perguntadas diretamente sobre elas, citaram a notificação como parte integral da assistência.

Por fim, no quarto e último tópico será abordado sobre a realização de educação em saúde frente à temática com a população assistida pelas UBS, onde todas as enfermeiras afirmaram que efetuam sim ações de promoção e prevenção.

E1 - "Sim. Conscientizar a denúncia; Empoderar dos seus direitos; falar e não se calar; não aceitar nem permitir".

E3 - "Sim. Fazemos na unidade na sala de espera palestras relacionadas as violências existentes e outros temas. Onde algumas nos procuram depois para conversar".

E5 - "Sim.

- Ações educativas (individuais e grupos)

- Prevenções, orientações, questionamentos por parte dos pacientes. Com participações de outros profissionais, psicólogos, assistente social. Planejamento familiar e equipes. NASF".

Nessa perspectiva, devido à alta complexidade da violência a promoção, prevenção e enfrentamento desse problema deve envolve não somente a participação dos profissionais, mas também toda a comunidade, que deve ser refletida no serviço de saúde. Dessa maneira, necessita impreterivelmente da articulação das políticas públicas e ações de assistência (MENEZES, 2014; GARBIN et al., 2015). Sendo assim, dito isto é importante relembrar duas políticas de enfrentamento a violência, são elas Política Nacional para as Mulheres (2004) e a Política Nacional de Enfrentamento à Violência Contra as Mulheres (2011), essas têm como objetivo enfrentar todas as formas de 
violência de gênero. Portanto, é dever da enfermagem promover ações de prevenção, tendo como base os protocolos instituídos no Brasil, mediante o exposto pelas participantes, as mesmas estão executando seu papel, desenvolvendo ações de prevenção, orientações e procurando empoderar as mulheres dos seus direitos, pois o melhor jeito de cuidar e presar pelo bem a assistência aos pacientes.

\section{CONCLUSÃO}

Portanto, verifica-se que, no decorrer do artigo foi possível esclarecer os seguintes pontos cruciais que seriam as ações de promoção e prevenção a violência contra a mulher, as dificuldades enfrentadas durante o atendimento, a realização e conhecimento sobre as notificações compulsórias e a realização de educação em saúde frente à violência contra a mulher. Sendo assim, com base nos resultados, observa-se que todos os objetivos traçados foram contemplados, como por exemplo a importância das ações de promoção e prevenção contra a violência a mulher, e além disso, foi observado também as dificuldades sentidas pelas profissionais frente o atendimento de casos de violência, percebeu-se certa dificuldade em estabelecer uma relação de confiança com as mulheres e assim uma recusa por parte delas em relatar a violência sofrida, dificultando o processo para a prestação adequada da assistência, logo, este é um ponto que deve ser trabalhado com uma conduta firme pelos profissionais. Nesse sentido, visto que é notório que os profissionais saiba executar o preenchimento da ficha, quando em diversos momentos da pesquisa mesmo sem serem perguntadas diretamente sobre elas, citaram a notificação como parte integral da assistência e, para finalizar, no que se diz respeito, a averiguação da formação complementar fornecida pelo hospital, como, educação permanente voltadas pra violência contra a mulher, obteve-se o resultado esperado nas hipóteses desta pesquisa, quando apenas uma das participantes recebeu treinamento, pois faz-se necessário, salientar que, quando averiguado se os profissionais realizavam educação em saúde voltadas a prevenção e promoção no combate a violência, todas as enfermeiras afirmaram participar destas ações. Por fim, é de suma importância que todos os profissionais sejam capacitados para identificação da violência, assim como para o manejo dessas situações, desenvolvendo melhor relação com as vítimas e um protocolo de atendimento multiprofissional eficaz. 


\section{REFERÊNCIAS}

AMARIJO CL, et al. Serviços de atendimento a mulheres em situação de violência doméstica/Services for the care of women in situations of domestic violence. Brazilian Journal of Health Review, v. 3, n. 1, p. 1306-1323, 2020.

AQUINO RCA, PASSOS MNS. Assistência De Enfermagem Às Mulheres Vítimas De Violência Sexual Na Atenção Básica. Revista Eletrônica Estácio Saúde, v. 7, n. 2, p. 42-47, 2018.

BRASIL. Lei $\mathrm{n}^{\circ} 11.340$ de 07 de Agosto de 2006. Lei Maria da Penha: cria mecanismos para coibir a violência doméstica e familiar contra a mulher... Diário Oficial da União. Brasília, DF, 08 ago. 2006. Disponível em: < de novembro de 2019>. Acessado em: 11 de Novembro de 2019.

BRASIL. Ministério da Saúde. Conselho Nacional de Secretários de Saúde (CONASS). “O desafio do Enfrentamento da Violência: Estratégias e Propostas". Brasília. 2008. Disponível em:

https://bvsms.saude.gov.br/bvs/publicacoes/desafio_enfrentamento_violencia.pdf>. Acessado em: 08 de Novembro de 2019.

CRUZ NPS, et al. Preenchimento da ficha de notificação compulsória de violência interpessoal e autoprovocada: desafios enfrentados pelo profissional de Saúde. REVISTA HUM@ NAE, v. 13, n. 2, 2019.

GARBIN CAS, et al. Desafios do profissional de saúde na notificação da violência: obrigatoriedade, efetivação e encaminhamento. Ciência \& Saúde Coletiva, 20, 18791890.2015.

GIL AC. Métodos e técnicas de pesquisa social. 5.ed. São Paulo: Atlas, 1999.

LEAL SMC, LOPES MJM. A violência como objeto da assistência em um hospital de trauma:" o olhar" da enfermagem. Ciência \& Saúde Coletiva, v. 10, p. 419-431, 2005.

MENEZES PRM, et al. Enfrentamento da violência contra a mulher: articulação intersetorial e atenção integral. Saúde e sociedade, v. 23, p. 778-786, 2014.

MINAYO MCS, SOUZA ER. Violência e saúde como um campo interdisciplinar e de ação coletiva. Hist. cienc. saúde-Manguinhos, Rio de Janeiro, v. 4, n.3, p. 513-531, nov. 1997.

PENNA LHG, et al. caracterização da violência sexual vivida por mulheres atendidas em unidade hospitalar de referência. Revista Enfermagem Atual In Derme, v. 81, n. 19, 2017.

PETRICIO P. Assistência À Mulher Vítima De Violência Sexual. Revista Saúde-UNG- Ser, v. 12, n. 1 (ESP), p. 28, 2018. 
RICHARDSON RJ. Pesquisa social: métodos e técnicas. 3. ed. São Paulo: Atlas,1999.

SALIBA 0, et al. Responsabilidade do profissional de saúde sobre a notificação de casos de violência doméstica. Rev Saúde Pública. 41(3):472-7; 2007.

SERAFIM VVD, et al. Violência contra a mulher e enfrentamento na percepção dos profissionais de saúde da atenção básica. 2019.

SILVA JG, et al. Direitos sexuais e reprodutivos de mulheres em situação de violência sexual: o que dizem gestores, profissionais e usuárias dos serviços de referência? 1. Saúde e Sociedade, v. 28, p. 187-200, 2019.

SILVA NNF, et al. Atuação dos enfermeiros da atenção básica a mulheres em situação de violência. Enfermagem Foco 2017; 8 (3): 70-4.

XAVIER AAP, SILVA EG. Assistência de enfermagem no atendimento de mulheres em situação de violência na atenção básica. Revista de Iniciação Científica e Extensão, v. 2, n. Esp. 2, p. 293-300, 2019. 


\section{Capítulo 2}

Caracterização do perfil de pacientes adultos acometidos pela hipertensão arterial sistêmica no Brasil: Uma revisão integrativa

Andressa Flores Mendes

Lílian Natália Ferreira de Lima

Jonathan Fernandes da Silva

Cristina Limeira Leite

Cristiana Maria de Araújo Soares Gomes
Patrícia dos Santos Silva Queiroz

Iracema Sousa Santos Mourão

Érika Ferreira Tourinho

Francisco Alves Lima Junior

Dennis Gonçalves Novais

Resumo: Traçar o perfil dos pacientes com HAS permite levantar características sociodemográficas, econômicas, condições ambientais, e a ocorrência de morbimortalidade, contribuindo para elaboração de um plano de saúde eficaz e em um planejamento fundamentado nas necessidades da população para desempenhar ações e serviços de promoção a saúde. 0 estudo tem como objetivo traçar o perfil da população adulta do Brasil acometida pela hipertensão arterial sistêmica. Consiste em uma pesquisa bibliográfica de abordagem qualitativa, utilizando o método revisão integrativa, a busca foi realizada a partir de consulta de artigos científicos originais e de pesquisa publicados entre os anos 2016 e 2021. Através da busca realizada nas bases de dados, foi incluído apenas 7 artigos que corresponderam inteiramente aos objetivos do estudo. Os resultados obtidos demostraram que os principais fatores de risco mais comumente encontrados em adultos acometidos pela HAS foram: idade, sexo, determinantes socioeconômicos, etnia, tabagismo e obesidade, com maior prevalência da HAS em indivíduos com idade avançada, o público feminino, baixo nível escolar, baixa renda e indivíduos de etnia negra.

Palavras-chave: Hipertensão Arterial Sistêmica, Fatores de risco, Prevalência. 


\section{INTRODUÇÃO}

Segundo a Organização Pan-Americana da saúde (OPAS) (2017) estima-se que 17,7 milhões de pessoas foram a óbito por doenças cardiovasculares em 2015, o que constitui em nível global 31\% de todas as mortes. É estimado que 7,4 milhões desses óbitos decorrem em virtude de doenças cardiovasculares. Diante dos levantamentos alarmantes apresentados encontra-se a Hipertensão arterial sistêmica (HAS) que contribui direta e indiretamente para $50 \%$ das mortes por doenças cardiovasculares (DCV).

De acordo com a Sociedade Brasileira de Hipertensão (2020) a Hipertensão Arterial (HA) é uma doença crônica não transmissível (DCNT), caracterizada como uma entidade clínica multifatorial que depende de condições genéticas, ambientais e sociais. É evidenciada por níveis tensionais elevados $\geq 140$ e/ou $90 \mathrm{mmHg}$, tem alta prevalência e baixas taxas de controle. A Organização Mundial da Saúde (OMS) estima que aproximadamente 600 milhões de pessoas tenham Hipertensão Arterial (HA), com progressão global de $60 \%$ dos casos até 2025 , além de cerca de 7,1 milhões de mortes anuais.

É difícil identificar uma única causa para a Hipertensão arterial, visto que existem diversos fatores que estão associados, podendo ser eles, socioeconômicos, ambientais, e alimentares, que procedendo sobre um pilar genético próprio, por um determinado tempo, acarreta ou favorece a ascensão da pressão arterial (CORREA et al., 2019).

Traçar o perfil dos pacientes com HAS permite levantar características sociodemográficas, econômicas, condições ambientais, e a ocorrência de morbimortalidade, contribuindo para elaboração de um plano de saúde eficaz e em um planejamento fundamentado nas necessidades da população para desempenhar ações e serviços de promoção a saúde (PORTAL DA SAÚDE, 2017). Como forma de subsidio para o controle e prevenção da hipertensão torna-se necessário conhecer o perfil desses pacientes. Nesse contexto levantou -se uma questão: Qual o perfil da população adulta do Brasil acometida pela hipertensão arterial sistêmica? Procurando respostas a esta questão norteadora este estudo foi desenvolvido com o objetivo de traçar o perfil da população adulta do Brasil acometida pela hipertensão arterial sistêmica. 


\section{METODOLOGIA}

Este estudo consiste em uma pesquisa bibliográfica de abordagem qualitativa com a utilização do método revisão integrativa.

A abordagem qualitativa valoriza a descrição e a explicação dos fenômenos estudados de forma coerente, objetivando respostas ao tema em questão e propiciando uma interpretação lógica dos dados coletados para fundamentar as conclusões de forma racional (CYRIACO et al., 2017)

O método revisão integrativa por sua vez permite sintetizar os resultados obtidos em pesquisas anteriores acerca da temática em estudo de forma sistemática, ordenada e abrangente, combina ainda dados de literatura teórica e empírica, proporcionando uma maior compreensão do tema (ERCOLE; MELO; CONSTANT, 2014). A revisão integrativa fundamentada na necessidade de amparar uma prática assistencial baseada em evidências científicas tem sido mencionada como ferramenta essencial no campo da saúde, uma vez que, condensa as pesquisas disponíveis sobre a temática em estudo e direciona a prática baseando-se em conhecimento cientifico (SOUSA; SILVA; CARVALHO, 2010).

A busca foi realizada a partir de consulta de artigos científicos originais e de pesquisa publicados entre os anos 2016 e 2021, indexados nas Bases de Dados da Biblioteca Virtual em Saúde/ BIREME (BVS), Base de Dados em Enfermagem (BDENF), Literatura Latino- Americana e do Caribe em Ciências da Saúde (LILACS) e Medical Literature Analysis and Retrieval System Online (MEDLINE). Os dados foram levantados durante o mês de maio de 2021, utilizando os descritores em Ciências da Saúde (DeCS): "Hipertensão Arterial", "Fatores de Risco", "Epidemiologia”, combinados da expressão booleana AND.

\section{RESULTADOS E DISCUSSÃO}

0 processo de seleção nas bases de dados, inicialmente, identificou um total de 187 artigos (16 na BDENF, 75 na LILACS e 96 na MEDLINE), que após a leitura minuciosa dos manuscritos e da aplicação dos critérios de exclusão e inclusão, resultaram em 7 artigos para esta revisão a partir dos critérios de elegibilidade, demostrado no Quadro 1. 
Quadro 1. Instrumento de coleta de dados: Sinopse dos artigos encontrados: título, ano, autor e bases de dados

\begin{tabular}{|c|c|c|c|c|}
\hline $\mathrm{N}^{\circ}$ & Título & Ano & Autor & Base de dados \\
\hline 1 & $\begin{array}{l}\text { Prevalência de hipertensão arterial } \\
\text { sistêmica e fatores associados em } \\
\text { homens e mulheres residentes em } \\
\text { municípios da Amazônia Legal. }\end{array}$ & 2016 & SILVA; et al & MEDLINE \\
\hline 2 & $\begin{array}{l}\text { Prevalência de hipertensão e fatores } \\
\text { associados em usuários do Programa } \\
\text { Saúde da Família de um município do } \\
\text { Nordeste brasileiro. }\end{array}$ & 2016 & $\begin{array}{c}\text { DAMAS; } \\
\text { NASCIMENTO; } \\
\text { NASCIMENTOSOBRI } \\
\text { NHO }\end{array}$ & LILACS \\
\hline 3 & $\begin{array}{l}\text { Tendência temporal da prevalência } \\
\text { de hipertensão arterial sistêmica no } \\
\text { Brasil. }\end{array}$ & 2017 & LOBO; et al & LILACS \\
\hline 4 & $\begin{array}{l}\text { Hipertensão Arterial autorreferida } \\
\text { em adultos residentes em Campinas, } \\
\text { São Paulo, Brasil: prevalência, fatores } \\
\text { associados e práticas de controle em } \\
\text { estudo de base populacional. }\end{array}$ & 2018 & ZANGIROLANI; et al & MEDLINE \\
\hline 5 & $\begin{array}{l}\text { Prevalência e Fatores Associados à } \\
\text { Hipertensão Arterial Sistêmica em } \\
\text { Adultos do Sertão de Pernambuco, } \\
\text { Brasil. }\end{array}$ & 2019 & SANTIAGO; et al & MEDLINE \\
\hline 6 & $\begin{array}{l}\text { Prevalência de hipertensão arterial } \\
\text { em adultos no município de São } \\
\text { Paulo e fatores associados }\end{array}$ & 2020 & FIÓRIO; et al & LILACS \\
\hline 7 & $\begin{array}{l}\text { Prevalência e fatores associados à } \\
\text { hipertensão arterial em adultos } \\
\text { residentes em Senador Canedo, } \\
\text { Goiás: estudo de base populacional, } \\
2016\end{array}$ & 2021 & BAZÍLIO; et al & LILACS \\
\hline
\end{tabular}

Fonte: Elaborado pelos autores.

Dos 7 estudos selecionados foram incluídos os objetivos, metodologia, resultados e as considerações finais. A síntese dos artigos incluídos na revisão apresenta-se a seguir: 


\section{Objetivo}

\section{ARTIGO 1}

Analisar a prevalência de hipertensão arterial sistêmica e fatores associados em homens e mulheres residentes em municípios da Amazônia Legal.

\section{Metodologia}

No estudo transversal de base populacional conduzido com 1.296 adultos de ambos os sexos foram coletados dados sociodemográficos, estilo de vida, antropométricos e pressão arterial, sendo considerados hipertensos os que apresentaram pressão arterial $\geq$ $140 / 90 \mathrm{mmHg}$ e/ou os que referiram uso de drogas antihipertensivas. As análises estatísticas foram feitas no módulo survey do programa Stata versão 11.0.

\section{Resultado}

A prevalência da HA sistêmica foi de $22,3 \%$. Após ajustes, as variáveis que se associaram à hipertensão nos homens foram a idade de 30 a 39 anos (RP ajustada $=2,69$; IC95\% 1,49 - 4,86), 40 a 49 anos (RP ajustada = 3,28; IC95\% 1,82 -5,93) e 50 a 59 anos (RP ajustada = 4,80; IC95\% 2,63 8,76), sobrepeso (RP ajustada =1,97; IC95\% 1,39 - 2,78), obesidade (RP ajustada = 3,32; IC95\% 2,32 - 4,75) e ser natural da região Norte ou Nordeste (RP ajustada =0,31; IC95\% 0,18 - 0,59). Entre as mulheres, associaram à hipertensão a idade de 40 a 49 anos (RP ajustada $=3,41$; IC95\% 1,91 - 6,07) e 50 a 59 anos (RP ajustada = 7,29; IC95\% 4,07 - 13,07); o consumo de vinho (RP ajustada = 0,31; IC95\% 0,10 - 0,97) e obesidade (RP ajustada = 2,39; IC95\% 1,65 -3,45).

\section{Considerações Finais}

A hipertensão arterial associou-se independentemente com a idade, estado nutricional e naturalidade nos homens. E nas mulheres com a idade, estado nutricional e tipo de bebida alcoólica.

\section{Objetivo}

\section{ARTIGO 2}

Estimar aprevalência de HAS e osfatores associados emindivíduos adultos cadastrados noPrograma Saúde da Família em SãoFrancisco do

Conde, no estado da Bahia.

\section{Metodologia}

Estudo epidemiológico de corte transversal, exploratório, de base populacional, em uma amostra aleatória de 456 indivíduos com idades iguais ou superiores a 18 anos, em São Francisco do Conde. A razão de prevalência foi utilizada para mensurar a associação, e o intervalo de confiança de 95\%, para medir a significância estatística entre as variáveis estudadas.

\section{Resultado}

A prevalência de hipertensão arterial foi de 51,80\% na população em geral entre os homens, 53,90\%; em indivíduos com excesso de peso, 57,95\%; entre os indivíduos $\geq 40$ anos, 72,08\%; e entre os que apresentavam adiposidade abdominal, 58,51\%. A hipertensão arterial demonstrou associação estatisticamente significativa na análise bruta e ajustada com idade $\geq 40$ anos e adiposidade abdominal. 


\section{Considerações Finais}

Observou-se elevadaprevalência dehipertensão, principalmente entre osindivíduos $\geq 40$ anos e aqueles que apresentaram adiposidade abdominal. Os resultados sugerem a necessidade de controledo sobrepeso e da adiposidade abdominal e o estímulo à adoção dehábitos de vida saudáveis.

\section{Objetivo}

\section{ARTIGO 3}

Analisar as prevalências de hipertensão arterial referida por adultos brasileiros acima de 20 anos, e verificar as variáveis socioeconômicas associadas em três períodos de tempo.

\section{Metodologia}

Os dados são da Pesquisa Nacional por Amostra de Domicílios (PNAD) realizada pelo Instituto Brasileiro de Geografia e Estatística (IBGE) nos anos de 1998 (196.439 participantes), 2003 (231.921) e 2008 (250.664). O desfecho era hipertensão arterial referida. As exposições principais eram renda em Reais e escolaridade em anos de estudos. A análise dos dados foi feita usando-se regressão de Poisson.

\section{Resultado}

Maiores prevalências de hipertensão arterial foram encontradas em pessoas com menor escolaridade, independentemente dos anos estudados e do sexo. Baixa renda esteve associada a maiores prevalências de hipertensão arterial independentemente dos anos estudados na amostra total e nas mulheres. Dentre os homens, esse efeito não foi verificado nos anos de 1998 e 2003. Já em 2008, homens de alta renda apresentaram maiores prevalências de hipertensão arterial, sugerindo modificação de efeito.

\section{Considerações Finais}

Dessa forma, o presente trabalho apontou o aumento das prevalências de hipertensão arterial nos períodos estudados, destacando sua associação negativa com aspectos socioeconômicos.

\section{Objetivo}

\section{ARTIGO 4}

Avaliar a prevalência de hipertensão arterial autorreferida em adultos de 20-5 anos, identificar os fatores associados, o uso dos Serviços de Saúde e as práticas de Controle da doença segundo posse ou não de plano de saúde.

\section{Metodologia}

Estudo transversal de base populacional realizado em Campinas-SP, em que foram analisados 957 adultos

\section{Resultado}

A prevalência de hipertensão arterial autorreferida foi de 14,1\%, revelando-se mais elevada em mulheres, em indivíduos com $\geq 40$ anos, nos que se declararam de cor preta,com menor escolaridade, nos inativos no lazer, ex-fumantes, naqueles com sobrepeso ou obesidade, nos que relataram duas ou mais doenças e que autoavaliaram a 
saúde como não sendo excelente/muito boa. Não foram detectadas desigualdades entrem hipertensos cobertos por planos de saúde e os SUS dependentes quanto ao acesso ao serviço, uso de medicamentos para controle e cuidados, mas houve diferenças quanto a prática de atividade física e o uso de dieta.

\section{Considerações Finais}

Apesar da equidade revelada quanto ao acesso à atenção à saúde, é incipiente a proporção de adultos que adota mudanças no estilo de vida para o controle da doença, reafirmando o papel central da gestão das políticas de saúde, que precisam trabalhar intersetorialmente.

\section{Objetivo}

\section{ARTIGO 5}

Estimar a prevalência everificar os aspectos associados à HAS em adultos do sertão de Pernambuco, Brasil.

\section{Metodologia}

Estudo de delineamentotransversal, com umaamostra aleatória deadultos de ambos os sexos. Foram considerados hipertensos aqueles que apresentaram pressão arterial sistólica $\geq 140 \mathrm{mmHg}$ e/ou diastólica $\geq 90 \mathrm{mmHg}$, além daqueles que relataram estar em tratamento com anti- hipertensivos. Informações demográficas,socioeconô-micas, comportamentais, antropométricas e de saúdee nutrição foram coletadas.

\section{Resultado}

A amostra foi composta por 416indivíduos e a prevalência de HAS foi de 27,4\% (IC95\% 23,2-32,0). No modelo final, foram identificados como preditoresindependentes da HAS a faixa etária a partir dos 40 anos $(p=0,000)$, classe econômica baixa $(p=0,007)$, tabagismo $(p=0,023)$, excesso de peso pelo índice de massa corporal $(p=0,003)$ e adultos com tolerância àglicose diminuída/diabetesmellitus ( $\mathrm{p}=0,012)$.

\section{Considerações Finais}

A prevalência de HAS éelevada e se relacionacom fatores de risco importantes, logo, são recomendáveis ações de prevenção e controle.

\section{Objetivo}

\section{ARTIGO 6}

Analisar o comportamento da prevalência de hipertensão arterial no município de São Paulo eseus fatores associado.

\section{Metodologia}

O presente trabalho utilizou os dados do Inquérito de Saúde no Município de São Paulo (ISA Capital), estudo transversal de base populacional executado no município de São Paulo. Foram utilizados dados de 1.667 e de 3.184 indivíduos em 2003 e 2015, respectivamente, com idade de 20 anos e mais. Fizeram- se análises descritivas das prevalências de HA com respectivos intervalos de 95\% de confiança. Análises simples e múltiplas foram realizadas para analisar possíveis associações com as variáveis socioeconômicas, demográficas e de estilo de vida por meio de regressão de Poisson. 


\section{Resultado}

A prevalência de hipertensãoarterial passou de 17,2\% em 2003 para 23,2\% em 2015. Os fatores associados àhipertensão foram: sexo feminino; idade (60 anos e mais); situação conjugal (casados, separados e viúvos); ter religião; baixa escolaridade; ter nascido no estado de São Paulo (exceto capital); estado nutricional (baixo peso, sobrepeso e obesidade); e ex-fumantes.

\section{Considerações Finais}

A prevalência de hipertensão autorreferida aumentou significativamente no período estudado em São Paulo. Considerando o impactodessa doença na sociedade, conhecendo sua atual prevalência e identificando seus Principais fatores associados, evidencias e a necessidade de intensificar atividades que contribuam para a prevenção desse agravo, atenuando os danos aos indivíduos e gastos públicos.

\section{Objetivo}

\section{ARTIGO 7}

Estimar a prevalência e fatores associados à hipertensão em adultos de Senador Canedo, Goiás, Brasil, no ano de 2016.

\section{Metodologia}

Inquérito transversal, de base populacional, com amostragem por conglomerados em três estágios. Foi aplicado questionário e realizadas aferições de peso, altura, circunferência da cintura, pressão arterial e dosagem do colesterol total.

\section{Resultado}

Nos 709 participantes, a prevalência de hipertensão foi de 23,6\% (IC95\% 19,3;28,6). Os fatores associados foram: inativos no lazer ( $\mathrm{RP}=1,7$ - IC95\% 1,1;2,5); circunferência de cintura aumentada (RP=5,9 IC95\%3,6;9,6); hipercolesterolemia ( $\mathrm{RP}=2,6$ - IC 95\% $1,3 ; 5,2)$; e idade $\geq 60$ anos (RP=2,9 - IC95\% 1,3;6,2).

\section{Considerações Finais}

A prevalência de hipertensão foi inferior à descrita para o Brasil em 2013. Inatividade física, acúmulo de gordura abdominal e idade foram fatores associados à Hipertensão.

Para que a prevenção e a promoção da saúde sejam feitas de forma satisfatória é necessário o conhecimento sobre a doença e dos fatores de risco que contribuem para o desenvolvimento da mesma ou das comorbidades associadas e para isso é necessário conhecer as características da população com HAS, com o intuito de criar, implementar e fortalecer políticas públicas que visem a manutenção e melhoria do estado de saúde.

Os fatores de risco associados encontrados nos estudos foram: sexo, idade, escolaridade, etnia, sobrepeso/obesidade, diabetes mellitus/ intolerância à glicose, 
tabagismo, etilismo e sedentarismo, além de fatores modificáveis como os determinantes socioeconômicos e o acesso inadequado aos cuidados de saúde.

Nos estudos analisados o sexo feminino apresentou maior prevalência de HAS. Este diferencial pode ser explicado pelo fato das mulheres apresentarem uma maior percepção aos sinais físicos e sintomas das doenças, pelo interesse com a própria saúde e por uma procura maior ao serviço de saúde, dessa forma, os problemas de saúde são diagnosticados mais previamente em mulheres do que em homens, que mesmo com recursos satisfatórios de atenção à saúde na sua localidade, são menos atentos à sua saúde e apresentam-se muita das vezes sem diagnóstico de hipertensão, mesmo tendo a doença (DAMAS; NASCIMENTO; NASCIMENTO SOBRINHO, 2016; FIÓRIO et al., 2020; ZANGIROLANI et al., 2018).

Apesar de ser uma patologia mais comum entre idosos, a HAS tem acometido uma parcela considerável dos adultos, atingindo, mais de 30 milhões de indivíduos dessa faixa etária no Brasil, uma hipótese para esse fator é o baixo desenvolvimento social e econômico e a possível relação desses fatores com a alta prevalência de DCNT, esse fator demostra a necessidade de se trabalhar as medidas preventivas o mais precocemente possível. (SANTIAGO et al., 2019).

Observou-se maior predisposição a desenvolver HAS indivíduos com idade superior a 40 anos. Apesar do crescente aumento nessa faixa etária é notório que essa doença tem relação direta e linear entre PA e idade, onde indivíduos com idade mais avançada tem um risco maior para desenvolver a HAS. Santiago et al (2019) destaca em seu estudo que essa condição se dar principalmente, pelo processo de arteriosclerose, onde o enrijecimento das paredes arteriais resultaria na elevação natural dos níveis tensionais, que ocorre normalmente devido às mudanças orgânicas que o envelhecimento acarreta. Dos sete estudos consideradas na análise, todos apresentaram relação direta da HAS com a idade elevada.

A variável cor da pele nos estudos demostrou-se mais prevalente em adultos com cor de pele preta, seguido de parda e branca. Literaturas denotam que populações negras apresentam maiores prevalências de hipertensão arterial. Esse fator se justifica pelo fato desse grupo conter um componente hereditário que afeta a captação celular de sódio e cálcio, interferindo na filtração glomerular (DAMAS; NASCIMENTO; NASCIMENTO SOBRINHO, 2016). Os mecanismos da etnia negra associada à HAS são 
complexos e ainda não esclarecidos completamente, nesse sentido, ao se analisar a relação entre HAS e a variável etnia deve-se levar em consideração fatores do contexto histórico, sociais e econômicos, uma vez que indivíduos com etnia negra estão mais propensos a vulnerabilidade social.

O nível de escolaridade é apontado na maioria dos estudos como um importante fator de risco para HAS. Fiório et al (2020) em seu estudo destaca como coeficiente as pessoas com níveis de escolaridade mais elevados possuírem mais informações e assim uma maior conscientização sobre cuidados com a saúde e prevenção de doenças. Ademais, é necessário também destacar as possíveis desigualdades no acesso, visto que, pessoas com maior nível escolar torna a dificuldade de acesso aos serviços de saúde menor.

O tabagismo também se mostrou associado a uma maior prevalência de HAS, principalmente em ex-fumantes. Fiório et al (2020) aponta como hipótese para este achado o fato de que a cessação do tabagismo possa desencadear sintomas de abstinência, como aumento de apetite e assim ganho de peso. Outrossim, é que a partir dos 45 anos de idade os indivíduos geralmente buscam tratamento para parar de fumar, e após um longo período de exposição resulta no surgimento dos primeiros desdobramentos crônicos das substancias. Em contrapartida, os indivíduos poderiam também ter parado de fumar depois do diagnóstico de hipertensão, visto que, é recomendado a cessação do tabagismo o mais breve possível.

A prevalência da HA na população adulta deve servir como subsidio para implementação de modelos de atenção à saúde de prevenção e controle de DCNT, com foco em intervenções sobre o controle do peso, níveis de colesterol, prática de atividades físicas, cuidado integral, vigilância das doenças e dos fatores de risco, objetivando a promoção e proteção da saúde (BAZÍLIO et al., 2021).

\section{CONSIDERAÇÕES FINAIS}

A partir da revisão dos dados da literatura pode-se considerar que os principais fatores de risco mais comumente encontrados em adultos acometidos pela HAS foram: idade, sexo, determinantes socioeconômicos (baixo nível de escolaridade e renda), etnia, tabagismo e obesidade. 0 perfil dos pacientes adultos acometidos pela hipertensão avaliada no estudo é caracterizado em sua maioria por indivíduos com idade avançada 
independente do sexo, o público feminino, baixo nível escolar, baixa renda e indivíduos de etnia negra atrelados a baixas condições socioeconômicas.

Levando em consideração que a intervenção terapêutica da HAS implica significativamente na redução da mortalidade e morbidade por DCV, se demostra de suma importância conhecer a prevalência e os principais fatores de risco para HAS, além de identificar grupos mais vulneráveis, contribuindo para criação e/ou efetivação de políticas de saúde mais equânimes.

Tendo em vista que os resultados desta revisão evidenciaram a vulnerabilidade social atrelada a maioria dos fatores de risco para hipertensão e salientado menor acesso e menor nível de informações relativas à saúde em grupos de baixo nível socioeconômico, fomenta-se a precisão de ampliação dos serviços de saúde nos grupos mais vulneráveis. Constata-se ainda a necessidade de acompanhamento de redes de atenção à saúde, garantindo a integralidade do cuidado. 0 acompanhamento multiprofissional deve ser sistemático e periódico, havendo ainda a necessidade de conhecer a realidade de cada paciente, facilitando a efetivação de medidas para redução e controle da HAS e consequentemente a diminuição da prevalência e de doenças relacionadas.

Portanto, é imprescindível que profissionais da saúde identifiquem os principais fatores de risco associados a HAS, para que possam efetuar medidas educativas e assistenciais, objetivando a prevenção e o controle dessa doença, além disso, medidas como estabelecer uma relação com o paciente com ênfase no diálogo e no envolvimento da família no tratamento, favorece o conhecimento do paciente acerca da sua patologia e consequentemente no aumento da adesão ao tratamento. Faz-se necessário ainda salientar a necessidade de políticas de promoção a saúde mais desenvolvidas, que visem minimizar as desigualdades socioeconômicas e a prevalência de HAS.

\section{REFERÊNCIAS}

BAZÍLIO, Gabriela Silvério et al. Prevalência e fatores associados à hipertensão arterial em adultos residentes em Senador Canedo, Goiás: estudo de base populacional, 2016. Epidemiologia e Serviços de Saúde, v. 30, p. e2019311, 2021. Disponível em: https://www.scielosp.org/article/ress/2021.v30n1/e2019311/. Acesso em: 20/05/2021. 
CORREA, Rafaela Rodrigues et al. Hipertensão arterial na etnia negra: uma revisão da terapia medicamentosa. Brazilian Journal of Surgery and Clinical Research - BJSCR, Vol.27, n.1, pp.157-159, 2019. Disponível em:

mastereditora.com.br/periodico/20190607_200307.pdf. Acesso em 26/03/2020.

CYRIACO, Aline Figueiredo Falcão et al. Pesquisa qualitativa: conceitos importantes e breve revisão de sua aplicação à geriatria/gerontologia. 2017. Disponível em: https://cdn.publisher.gn1.link/ggaging.com/pdf/v11n1a02.pdf. Acesso em: $15 / 06 / 2021$.

DAMAS, Liliane Vidal de Oliveira; NASCIMENTO, Mônica de Andrade; NASCIMENTO SOBRINHO, Carlito Lopes. Prevalência de hipertensão e fatores associados em usuários do Programa Saúde da Família de um município do Nordeste brasileiro. Rev. bras. hipertens, p. 39-46, 2016. Disponível em: https://pesquisa.bvsalud.org/portal/resource/pt/biblio-881158 Acesso em: 20/05/2021.

EID, Leticia Palota et al. Hábitos alimentares e fatores de risco para hipertensão arterial sistêmica em escolares. Arquivos de Ciências da Saúde, v. 26, n. 1, p. 9-14, 2019. Disponível em:

http://www.cienciasdasaude.famerp.br/index.php/racs/article/view/1396/777. Acesso em 25/03/2020.

ERCOLE, Flávia Falci; MELO, Laís Samara de; ALCOFORADO, Carla Lúcia Goulart Constant. Revisão integrativa versus revisão sistemática. Revista Mineira de Enfermagem, v. 18, n. 1, p. 9-12, 2014. Disponível em: http://www.reme.org.br/artigo/detalhes/904. Acesso em: 05/05/2021.

FIÓRIO, Cleiton Eduardo et al. Prevalência de hipertensão arterial em adultos no município de São Paulo e fatores associados. Revista Brasileira de Epidemiologia, v. 23, p. e200052, 2020. Disponível em: https://www.scielosp.org/article/rbepid/2020.v23/e200052/. Acesso em: 20/05/2021.

LOBO, Larissa Aline Carneiro et al. Tendência temporal da prevalência de hipertensão arterial sistêmica no Brasil. Cadernos de Saúde Pública, v. 33, p. e00035316, 2017. Disponível em: https://www.scielosp.org/article/csp/2017.v33n6/e00035316/pt/. Acesso em: 20/05/2021.

Organização Pan-Americana da saúde (OPAS). Doenças Cardiovasculares. 2017. Disponível em:https://www.paho.org/bra/index.php?option=com_content\&view=article\&id=5253: doenca s-cardiovasculares\&Itemid=1096. Acesso em 25/03/2020. 
PORTAL DA SAÚDE. Roteiro para Construção do Perfil Epidemiológico.2017. Disponível em:http://portal.saude.pb.gov.br/infosaudef/assets/docs/Roteiro_Perfil_Epidemiologic o.pdf. Acesso em:28/02/2021.

PORTELA, R. S.; BARBOSA, A. M.; MARTINS, M. A.; PELAZZA, B. B.; LEITE, G. R.; PAULA, C. R. Prevalência de fatores de risco cardiovasculares e fatores associados em usuários de unidades de saúde. Rev Enferm UFPE, v. 10, n. 9, p. 3232-3240, 2016. Disponível em: https://periodicos.ufpe.br/revistas/revistaenfermagem/. Acesso em: 20/04/2021.

SANTIAGO, Emerson Rogério Costa et al. Prevalência e fatores associados à hipertensão arterial sistêmica em adultos do sertão de Pernambuco, Brasil. Arquivos Brasileiros de Cardiologia, v. 113, n. 4, p. 687-695, 2019. Disponível em:

https://www.scielo.br/j/abc/a/SQKrhFy8BzvMFN6vgVFCs9x/?lang=pt. Acesso em: 20/05/2021.

SILVA, Elcimary Cristina et al. Prevalência de hipertensão arterial sistêmica e fatores associados em homens e mulheres residentes em municípios da Amazônia Legal. Revista Brasileira de Epidemiologia, v. 19, p. 38-51, 2016. Disponível em:

https://www.scielosp.org/article/rbepid/2016.v19n1/38-51/pt/. Acesso em: 20/05/2021.

SOUZA, Marcela Tavares de; SILVA, Michelly Dias da; CARVALHO, Rachel de. Revisão integrativa: o que é? Como fazer isso? Einstein (São Paulo), São Paulo, v. 8, n. 1, pág. 102106, março de 2010. Disponível em:

http://www.scielo.br/scielo.php?script=sci_arttext\&pid=S167945082010000100102\&lng=en\&nrm=iso. Acesso em: 06/05/2021.

World Health Organization. Guideline: Sodium intake for adults and children [Internet]. Genebra: World Health Organization; 2012. Disponível em: Disponível em: https://apps.who.int/iris/bitstream/handle/10665/77985/9789241504836_eng.pdf?s equence=1. Acesso em: 05/04/2021.

WORLD HEALTH ORGANIZATION. Hipertension, 2019. Disponível em:https://www.who.int/es/news-room/fact-sheets/detail/hypertension. Acesso em $20 / 03 / 2021$.

World Health Organization. Pan American Health Organization. Hypertension [Internet]. Pan American Health Organization; 2018. Disponível em: https://www.paho.org/hq/index.php?option=com_topics\&view=article\&id=221\&Itemid =4087 8\&lang=en. Acesso em: 20/03/2021.

World Health Organization - WHO. Global status report on noncommunicable diseases 2014 [Internet]. Geneva: World Health Organization; 2014. Disponível em: https://www.who.int/nmh/publications/ncd-status-report-2014/en/. Acesso em: $08 / 04 / 2021$. 
ZANGIROLANI, Lia Thieme Oikawa et al. Hipertensão arterial autorreferida em adultos residentes em Campinas, São Paulo, Brasil: prevalência, fatores associados e práticas de controle em estudo de base populacional. Ciência \& Saúde Coletiva, v. 23, p. 1221-1232, 2018. Disponível em: https://www.scielosp.org/article/csc/2018.v23n4/12211232/pt/. Acesso em: 20/05/2021. 


\section{Capítulo 3}

Metodologias de ensino em graduação de enfermagem

\section{Dhonnel Oliveira da Silva \\ Catilena Silva Pereira \\ Rafael Oliveira Chaves \\ Silvana Nascimento Soares \\ Edson Ferreira de Araújo}

Iracema Sousa Santos Mourão

Renilda da Silva Soares

Francisco Alves Lima Junior

Karla Vanessa Morais Lima

Cristiana Maria de Araújo Soares Gomes

Resumo: 0 papel dos educadores de enfermagem no desenvolvimento de carreira inclui: tornar-se educadores, facilitadores, agentes de mudança, consultores, pesquisadores e líderes. 0 presente estudo teve como objetivo analisar, ampliar e sintetizar os métodos mais utilizados no ensino em graduação de enfermagem. Para alcançar a concretização do objetivo proposto, realizou-se uma pesquisa bibliográfica do tipo exploratória, descritiva e qualitativa. Foram utilizados como fontes bibliográficas artigos de periódicos científicos, publicados no período de janeiro de 2017 a setembro de 2020, 3 anos 9 meses, no idioma português. Os resultados foram que, aprendizado baseado em evidência é um método ativo, espera-se obter conhecimento por meio do comportamento, inspirando assim uma aprendizagem significativa. A prática baseada em evidências é um método notório de melhorar a eficácia clínica e apoiar a tomada de decisão acadêmica e profissional. No cotidiano de trabalho e na formação do enfermeiro, o aspecto moral da prática cotidiana fundamenta-se na relação entre moralidade e educação, fundamenta-se no pensamento crítico, no desenvolvimento da capacidade reflexiva e na crítica à sociedade e à próprias relações sócio-educativas dos sujeitos desse processo.

Palavras-chave: Enfermagem. Graduação. Educação em enfermagem. Ensino Superior. 


\section{INTRODUÇÃO}

Falar em educação já é uma tarefa difícil, mas diante das diferentes realidades da formação do enfermeiro e das diferentes origens socioeconômicas de cada região do país, fica ainda mais difícil falar sobre a graduação em enfermagem no contexto nacional. A escassez concentra-se principalmente na divulgação das recomendações atuais de educação e seus objetivos e resultados educacionais (CARBOGIM, et al. 2019; CARVALHO, et al. 2020; GÓMEZ, 2019).

Como se sabe, a formação do enfermeiro vem acompanhada de mudanças paradigmáticas, embora essa visão não surpreenda, é preciso ressaltar que é hora de agir. Tais mudanças devem ser iniciadas por docentes de enfermagem de todo o país, envolvendo os seguintes aspectos: o conteúdo, o tempo e os métodos que podem proporcionar ensino e preparação para os alunos de enfermagem no século XXI (ARAUJO, et al. 2019; CARBOGIM, et al. 2019)

De acordo com a American Nurses Association, o papel dos educadores de enfermagem no desenvolvimento de carreira inclui: tornar-se educadores, facilitadores, agentes de mudança, consultores, pesquisadores e líderes (TWEDELL, 2005).

Para promover a integração do SUS no Brasil, o Ministério da Educação (MEC) e o Ministério da Saúde (MS) elaboraram a resolução CNE / CESno03 (1) de 11 de março de 2001, que define a necessidade de atualização do padrão do Programa Nacional de PósGraduação em Enfermagem (DCENF). Educação continuada flexível, crítica, reflexiva e multifuncional para encontrar soluções aos desafios da saúde da população (BRASIL, 2001).

Essas diretrizes norteiam mudanças no processo de formação do enfermeiro. Portanto, expressaram a necessidade de formar profissionais qualificados, de acordo com os princípios da reforma sanitária brasileira e do Sistema Único de Saúde (SUS), para ter senso de responsabilidade social e compromisso com o cidadão, como promotor da saúde humana integral. A especificidade dessas diretrizes é obtida por meio da mobilização de propostas nesta categoria a partir das perspectivas coletiva, cívica e ética das disciplinas envolvidas no processo de formação do enfermeiro (ARAUJO, et al, 2019; CARVALHO, et al, 2020; GÓMES, 2019).

A enfermagem moderna tem um conjunto de valores a partir dos quais uma escala de avaliação bem projetada pode ser desenvolvida para dar sentido profissional 
de ação e significado. Florence Nightingale (Florence Nightingale) identificou esses valores como fundadores da enfermagem, formando uma espécie de integração, a saber: valor social, valor ético, valor útil e valor verdadeiro (RUFINO, et al. 2020; TEXEIRA, 2017; CARVALHO, et al. 2020).

Nesse contexto, o presente estudo tem como objetivo analisar, ampliar e sintetizar os métodos mais utilizados no ensino em graduação de enfermagem.

\section{METODOLOGIA}

Realizou-se uma pesquisa bibliográfica do tipo exploratória, descritiva e qualitativa. Bibliográfica porque permite a sondagem de matérias já publicados em bases cientificas. Descritiva porque favorece descrever o desenvolvimento do problema e seu manejo revisados. Já a exploratória consente no aprofundamento das matérias sondadas, mais familiaridade com o problema. Quanto ao tipo qualitativo, é um método de investigação científica que se foca no caráter subjetivo do objeto analisado (GIL, 2008).

Foram utilizados como fontes bibliográficas artigos de periódicos científicos, publicados no período de janeiro de 2017 a setembro de 2020, 3 anos 9 meses, no idioma português. A busca de materiais foi realizada nos bancos de dados online MEDLINE, LILACS e SCIELO integrante do sistema BIREME. Os descritores utilizados foram, enfermagem, graduação, educação em enfermagem e ensino superior.

Para início, foi realizada uma leitura estritamente de cunho exploratória e seletiva, para examinar o quanto os periódicos atendiam e interessavam ao objetivo, para selecionar de fato aqueles que contemplavam o objetivo proposto. A seguir, de forma analítica, ordenada e sumarizada, foram coletadas as informações necessárias para elaboração dos resultados. Por último, de forma interpretativa, o resultado foi elaborado relacionando o conhecimento dos autores com o problema do estudo. Os princípios éticos foram respeitados, na medida em que as obras e os autores foram devidamente referenciados no texto, em consonância as determinações da Lei dos Direitos Autorais no 9.610, de 19 de fevereiro de 1998. 


\section{RESULTADOS E DISCUSSÕES}

Os resultados mostram informações relevantes sobre o plano estratégico para o ensino de graduação em enfermagem. No processo de ensino de estudantes de enfermagem, cinco estratégias são enfatizadas: aprendizagem baseada em equipe, método de simulação, prática baseada em evidências (pbe), estudo de caso e educação baseada em problemas (pbl).

\subsection{APRENDIZAGEM BASEADA EM EQUIPES}

A fim de desenvolver as competências necessárias ao desempenho profissional, são utilizados na formação diversos métodos e técnicas de educação construtivista, incluindo a aprendizagem baseada em equipe (ABE), que pode melhorar o processo de ensino através da modificação dos métodos tradicionais. A base teórica da ABE é o construtivismo, com base no qual os professores podem se tornar facilitadores da aprendizagem a partir do diálogo e da interação entre os alunos (incluindo habilidades de comunicação e trabalho em equipe), e permitir que os alunos reflitam sobre a prática. Isso levou a uma mudança no raciocínio anterior (SAKAMOTO, et al. 2020; ALMEIDA, et al. 2018).

Autores com experiência nesta metodologia relatam que os alunos devem ser responsáveis pela preparação pessoal para trabalhos em grupo - pré-leitura ou outras atividades programadas pelo professor, como participação em experimentos, conferências, filmes, realização de entrevistas, etc. A preparação para cada atividade préaula é uma etapa básica. Esses autores também apontaram que se não concluírem as tarefas da pré-aula individualmente, os alunos não poderão contribuir para o desempenho da equipe. A falta deste tipo de preparação pode dificultar o desenvolvimento da coesão da equipa e fazer com que os alunos preparados se sintam insatisfeitos por pensarem que os seus próprios colegas dispostos e / ou menos qualificados ficarão sobrecarregados (SAKAMOTO, et al. 2020; ALMEIDA, et al. 2018; RUFINO, et al. 2020).

\subsection{MÉTODOS DE SIMULAÇÃO}

O uso de simuladores mais avançados, tecnologia de som e imagem para simular no ensino de enfermagem tornou-se uma realidade cada vez mais popular, principalmente no início deste século, tornou-se a primeira ferramenta educacional para 
as pessoas usarem a prática em conjunto com o contexto real (ALMEIDA, et al. 2018; ARAUJO, et al. 2019).

Por outro lado, a simulação clínica é um método desenvolvido para aprimorar o raciocínio e o pensamento crítico, que pode qualificar as habilidades de avaliação e tomada de decisão exigida na prática de enfermagem (ALMEIDA, et al. 2018; CARBOGIM, et al. 2019) ARAUJO, et al. 2019).

Devido à capacidade de reproduzir sons e imagens, o simulador é dividido em baixa, média e alta fidelidade. Os simuladores de baixa fidelidade são estáticos e tem menor reprodução da realidade, os de média fidelidade têm maior capacidade de realismo e podem auscultar a respiração e os sons cardíacos, o que pode identificar diferentes diagnósticos. 0 efeito de alta fidelidade é muito realista: de acordo com os procedimentos operacionais do professor, os movimentos do tórax, olhos, pulmões, coração, intestinos e vozes humanas que respondem à luz mostram sangramento e secreções (DAVI, et al. 2018; RIBEIRO, et al. 2020; OLIVEIRA, et al. 2019).

\subsection{PRÁTICA BASEADA EM EVIDÊNCIA (PBE)}

A prática baseada em evidências é uma forma de melhorar a qualidade dos cuidados de saúde. O método envolve definir problemas, pesquisar e avaliar rigorosamente as evidências disponíveis (principalmente pesquisas), implementar as evidências na prática e avaliar os resultados obtidos. Ele também combina as capacidades clínicas dos profissionais e as preferências do cliente para decisões de saúde (LIMA, et al. 2020; SILVA, MERCÊS, 2018).

Vários autores enfatizam que a PBE é importante para apoiar a prática profissional e descrevem que a implementação da PBE é essencial para alcançar eficácia, confiabilidade e segurança nas práticas de saúde. Além disso, os resultados encontrados na revisão sistemática mostram que mesmo que várias barreiras ao uso da PBE tenham sido identificadas, os profissionais ainda acreditam que a PBE pode melhorar a qualidade do atendimento e a evolução clínica dos pacientes (SCHNEIDER, PEREIRA, FERRAZ, 2018).Quando o cuidado é prestado dessa forma como um princípio orientador, as intervenções se tornam mais eficazes e os resultados podem fornecer um cuidado melhor; os profissionais de saúde precisam aprender a adquirir e interpretar os 
dados a fim de praticar com base nas evidências das melhores práticas (SILVA, MERCÊS, 2018; TEIXEIRA, 2017).

Na enfermagem, a implementação de práticas baseadas em evidências pode ajudar a transformar práticas baseadas em tradições, rituais e tarefas em práticas reflexivas baseadas em conhecimentos científicos, contribuindo para melhorar a qualidade da assistência prestada aos pacientes e familiares (SCHNEIDER, PEREIRA, FERRAZ, 2018).

\section{ESTUDO DE CASO}

Ao longo do processo de ensino, os alunos são aconselhados a usar o processo de enfermagem como método de solução de problemas e método de raciocínio para apoiar julgamentos clínicos adequados. Os estudos de caso podem ser uma ferramenta valiosa para os professores encontrarem estratégias para ajudá-los a aprender. Trata-se de uma exploração de casos obtidos por meio de coleta detalhada de dados, envolvendo múltiplas fontes de informação que devem ser relevantes para a tomada de decisão (DAVID, 2018; CARVALHO, et al. 2020).

Este método pode não só estudar os problemas e necessidades dos pacientes, familiares e comunidades, mas também fornecer subsídios para encontrar as melhores estratégias de resolução dos problemas, de forma que a correlação entre teoria e prática seja maior, o que favorece o ensino teórico dos alunos, absorção e aplicação prática para solução dos possíveis problemas (GÓMEZ, 2019; LIMA, et al. 2020).

EDUCAÇÃO BASEADA EM PROBLEMAS - PBL

O PBL foi proposto por Barrows na década de 1960 e foi estabelecido na faculdade de medicina da Universidade McMaster no Canadá. Logo depois, ela foi adotada pela Universidade de Maastricht, na Holanda. É apoiado pela teoria da investigação de John Dewey e confirmado a partir de uma perspectiva construtivista, especialmente sob a orientação do ensino de estilo antigo de piagetiana (SAMPAIO, 2018; SAKAMOTO, et al. 2020).

Partindo da abordagem dos princípios filosóficos subjacentes ao PBL, algumas pessoas acreditam que essa forma de aprendizagem não pode ser considerada uma mera técnica, pois envolve mudança de atitudes em relação ao processo (SAMPAIO, 2018; SAKAMOTO, et al. 2020; ARAUJO, et al. 2019). 


\section{CONSIDERAÇÕES FINAIS}

A pesquisa bibliográfica do tipo exploratória, descritiva e qualitativa, mostrou-se adequada ao objetivo central da pesquisa, que é analisar, ampliar e sintetizar os métodos mais utilizados no ensino em graduação de enfermagem.

A leitura estritamente de cunho exploratória e seletiva, de forma analítica, ordenada e sumarizada, permitiu construir uma visão geral sobre os métodos de ensino mais utilizadas na graduação em Enfermagem e fornecer material significativo para a fundamentação da problemática pesquisada.

Foi possível depreender que no processo de ensino de estudantes de enfermagem, cinco estratégias são mais enfatizadas: aprendizagem baseada em equipe, método de simulação, prática baseada em evidências (PBE), estudo de caso e educação baseada em problemas (PBL).

Em síntese, no cotidiano de trabalho e na formação do enfermeiro, o aspecto moral da prática cotidiana fundamenta-se na relação entre moralidade e educação, fundamenta-se no pensamento crítico, no desenvolvimento da capacidade reflexiva e na crítica à sociedade e à próprias relações sócio-educativas dos sujeitos desse processo.

\section{REFERÊNCIAS}

ALMEIDA, D. R. de. et al. A simulação como estratégia de ensino aprendizagem em enfermagem: uma revisão integrativa. Rev. Educ. Saúde, 2018.

ARAUJO, C. R. C. et al. Contribuição das Ligas Acadêmicas para Formação em Enfermagem. Enferm. Foco, Brasília, 2019.

BRASIL, Ministério da Educação. Parecer CNE/CES no․ 1133, de 07 de agosto de 2001. Diretrizes curriculares nacionais dos cursos de graduação em enfermagem, medicina e nutrição. Brasília: Ministério da Educação; 2001.

CARBoGiM, F. C. et al. Modelo de ensino ativo para o desenvolvimento do pensamento crítico. Rev. Bras. Enferm. vol.72 no.1 Brasília, 2019.

CARVALHO, D. P. S. R. P. et al. Pensamento crítico em estudantes de Enfermagem de duas regiões brasileiras. Rev. Bras. Enferm. vol.73 no.1, Brasília, 2020 .

DAVID, F. S. Evolução para a práxis emancipatória: desenvolvimento do método de simulação realística no ensino de graduação em enfermagem. Online braz. j. nurs. 2018. 
GIL, A. C. Como elaborar projetos de pesquisa. 4. ed. São Paulo: Atlas, 2008.

GÓMEZ, M. A. J. O pensamento reflexivo e crítico no currículo de enfermagem. Rev. Latino-Am. Enferm. Ribeirão Preto, 2019.

LIMA, T. et al. Exame físico na enfermagem: avaliação do conhecimento teórico-prático. Nursing. Säo Paulo, 2020.

OLIVEIRA, S. N. de. et al. Simulador de baixo custo para punção venosa periférica: da confecção à avaliação. Rev. Enferm. UERJ. 2019.

RIBEIRO, K. R. B. et al. Influência do lúdico no ensino de enfermagem: uma pesquisaação. Rev. Pesqui. UFRJ. 2020.

RUFINO, C. G. et al. Pensamento crítico e as estratégias de ensino para docentes do curso de graduação em enfermagem. Rev. Enferm. UERJ . 2020.

SAKAMOTO, S. R. et al. Aprendizagem baseada em equipes: um ensaio clínico randomizado na graduação em enfermagem. Rev. Bras. Enferm. vol.73 no.2 Brasília, 2020 .

SAMPAIO, C. L. Aprendizagem baseada em problemas no ensino da Tanatologia, no curso

SCHNEIDER, L. R. PEREIRA, Rui, P. G. FERRAZ, Lucimare. A prática baseada em evidência no contexto da Atenção Primária à Saúde. Saúde debate. 2018.

SILVA, L. A. G. P. MERCÊS, N. N. A. Multiple case study applied in nursing research: a case report. Rev Bras Enferm. 2018.

TEIXEIRA, E. Em tempos de novas diretrizes curriculares nacionais (den) para o curso de graduação em enfermagem Rev. Enferm. UFSM. 2017.

TWEDELL, D. International Perspectives in Continuing Education. J CONTIN. EDUC. NURS. 2005. 


\section{Capítulo 4}

Avaliação da potabilidade da água de poços do assentamento Palmares, Araguatins-To

Igor Garcia Moura

Lilian Natalia Ferreira de Lima

Cléber Silva e Silva

Enio Rocha Santos

Ricardo Henrique Paes Barreto Peixoto
Antônio Silva Machado

Marcia Guelma Santos Belfort

Herculano Rodrigues Silva

Wilma Helena da Rocha Falcão

Patrick Assunção Mourão

Resumo: A água subterrânea tem se mostrado um elemento de extrema relevância para o consumo das famílias, especialmente nas localidades onde o saneamento é precário ou inexistente, por esse motivo, é fundamental que os parâmetros de qualidade deste recurso sejam continuamente monitorados. 0 presente estudo teve como objetivo avaliar os parâmetros físico-químicos da água de dois poços do assentamento Palmares, comparando-os com os valores máximos permitidos na legislação. As coletas das amostras ocorreram em 5 dias consecutivos, compreendendo o período de 16 a 20 de outubro de 2017, em dois pontos de captação. Para determinação dos parâmetros físicoquímicos, foram utilizados termômetro, turbidímetro, pHmetro e sonda multiparamétrica. Os dispostos no Anexo XX da Portaria de consolidação n ${ }^{\circ}$ 5/2017 foram utilizados como valores de referência para os parâmetros avaliados. Os resultados obtidos demonstraram inadequação de alguns parâmetros aos requisitos da legislação regulamentadora, indicando que a água dos poços avaliados não está adequada ao padrão de potabilidade. Considerando que o recurso hídrico subterrâneo consiste na única fonte de abastecimento para as famílias do assentamento Palmares, o acompanhamento das condições ambientais e sanitárias, as análises regulares dos parâmetros de qualidade da água, bem como a correção desses parâmetros representam alternativas importantes à estrutura precária de saneamento observada no local de estudo.

Palavras-chave: Água subterrânea, Potabilidade, Parâmetros físico-químicos. 


\section{INTRODUÇÃO}

As águas subterrâneas representam 97\% de toda a água doce e líquida do planeta e são encontradas abaixo da superfície do solo, preenchendo os poros das rochas e dos sedimentos, formando assim os aquíferos. Estes, portanto, são classificados como o maior reservatório de água potável do planeta, sendo indispensáveis à segurança hídrica global. Nos campos e nas periferias das cidades, onde geralmente não existe rede pública de abastecimento, o recurso hídrico subterrâneo surge, na maioria das vezes, como a única opção de água potável. Ademais, a perfuração de poços particulares também representa uma fonte alternativa e suplementar em resposta às falhas no abastecimento público ou ao seu menor custo diante dos valores cobrados pela água fornecida pelos prestadores do serviço público (BERTOLO et al., 2019).

Segundo o Ministério da Saúde, a água para consumo humano é toda água potável destinada à ingestão, produção e preparo de alimentos e à higiene pessoal, independentemente de sua origem. Ele a classifica ainda, como um bem essencial para a garantia da saúde e qualidade de vida da população, devendo ser distribuída em quantidade suficiente e dentro do padrão de potabilidade preconizado pela legislação vigente. Este padrão de potabilidade estabelece os valores máximos permitidos para parâmetros físicos, químicos, microbiológicos, organolépticos, cianobactérias/cianotoxinas e de radioatividade, definidos no Anexo XX da Portaria de Consolidação $n^{\circ} 5 / 2017$, que dispõe sobre a Potabilidade da Água para Consumo Humano (BRASIL, 2021).

No entanto, a mera existência de normas regulamentadoras não assegura a certificação e a garantia de padrões de qualidade da água consumida pela população. Por isso, é fundamental que este assunto seja discutido e vigiado por toda a sociedade civil, incluindo gestores e acadêmicos a fim de assegurar maior legitimidade do direito à água potável (GOBIRA E DUARTE, 2018). A contaminação dos recursos hídricos em áreas rurais decorre basicamente da presença de esgoto não tratado e da atividade agropecuária, onde os fertilizantes e pesticidas usados na produção agrícola, bem como os dejetos oriundos da criação de animais atingem o lençol freático através da infiltração no solo, ou mesmo caindo diretamente na água utilizada para consumo (MIRLEAN et al., 2005). 
O abastecimento de água na zona rural do município de Araguatins-TO provém, em sua maior parte, da captação de água através de poços semiartesianos de pouca ou grande profundidade. Nas pequenas comunidades e assentamentos de reforma agrária, estes poços assumem papel relevante na saúde pública local, visto que são, geralmente, de uso coletivo. Apesar disso, sabe-se que estes poços não são regularmente testados quanto à sua qualidade, fato que impossibilita determinar a existência de contaminantes e outros elementos que podem estar presentes na água, prejudicando sua potabilidade.

Compreendendo que as famílias residentes no assentamento Palmares possuem condições socioeconômicas desfavoráveis e pouco acesso à infraestrutura municipal de saneamento básico, torna-se imprescindível determinar os riscos que o consumo de água de poços sem o devido tratamento oferece à saúde dessas pessoas. Nesse contexto, fica evidenciada a necessidade do desenvolvimento deste estudo como meio de contribuir para a construção de uma base dados confiáveis, que poderá servir de subsídio às ações de promoção à saúde e às intervenções estruturais factíveis pelo poder público local. Diante do exposto, o presente estudo teve como objetivo, avaliar os parâmetros físico-químicos da água de dois poços do assentamento Palmares, comparando-os com os valores máximos permitidos na legislação.

\section{METODOLOGIA}

A pesquisa foi realizada no assentamento Palmares, distante vinte e oito quilômetros da cidade de Araguatins. Este assentamento foi criado pelo Instituto Nacional de Colonização e Reforma Agrária, INCRA, no dia 24 de fevereiro do ano de 2009. Aloja 50 famílias em 450 ha, sendo que 67,16 ha são de reserva do assentamento. A distribuição de água no assentamento era realizada por meio de poços semiartesianos implantados na agrovila do assentamento. Esse poço e composto por uma estrutura que envolve uma bomba elétrica, caixa d'água, encanação. Esse conjunto de equipamentos constituiu o abastecimento de água na agrovila do assentamento. Essas estruturas de abastecimentos de água foram implantadas dois anos após a criação do assentamento. Seu funcionamento e abastecimento não atendem as necessidades das famílias.

A definição dos pontos de amostragem (Poços) foi feita levando-se em consideração o uso da água pelos moradores. Os pontos de captação de água no assentamento são o poço semiartesiano fechado (PT2) e o poço aberto (PT1), ambos 
foram utilizados para esse estudo, suas localizações são S 5.479242 W 48.045949 e S 5.474478 W 48.043355 respectivamente.

As amostras de água para análise físico-química foram coletadas, em frascos de polietileno previamente limpos com ácido nítrico $10 \%$ por 48 horas, sendo estes lavados com água destilada e água ultrapura. Todas as amostras foram identificadas e acondicionadas para serem transportadas e conservadas até o laboratório Aqua, localizado em Imperatriz (MA), distante $100 \mathrm{~km}$ do local das coletas. Foram realizadas cinco campanhas consecutivas de água amostrando-se em cada um dos pontos amostrais, 03 amostras de cada ponto, com frequência diária, durante o período compreendido entre os dias 16 a 20 de outubro de 2017, sempre às 08:40h.

Foram analisados parâmetros físicos e químicos usando-se metodologia padrão. Os parâmetros temperatura da água, $\mathrm{pH}, \mathrm{OD}$, condutividade e turbidez foram medidos em campo, em cada ponto de coleta com equipamentos específicos, imediatamente logo após a coleta das amostras. Os demais parâmetros avaliados foram: temperatura, dureza total, alcalinidade total, nitrito, nitrato e sólidos totais dissolvidos. Além do termômetro de filamento de mercúrio e pHmetro, foram utilizados os métodos titulométrico, potenciométrico, gravimétrico e espectrofométrico para avaliação dos parâmetros. Em seguida, os valores obtidos foram comparados com os valores máximos estabelecidos pela Anexo XX da Portaria de Consolidação n5/2017 (Brasil, 2021).

\section{RESULTADOS E DISCUSSÃO}

Os parâmetros físico-químicos fazem parte de uma série de parâmetros que atestam a qualidade da água. Para que a água seja considerada adequada para o consumo humano todos os seus parâmetros devem estar em conformidade com Anexo XX da Portaria 5/2017, que estabelece os valores máximos permitidos (VMP). Os resultados obtidos para a presente investigação estão descritos na Tabela 1. 
Tabela 1 - Valores médios dos parâmetros físico-químicos obtidos para o poço aberto e o poço fechado e valor máximo permitido na legislação.

\begin{tabular}{|c|c|c|c|}
\hline $\begin{array}{c}\text { Parâmetros físico- } \\
\text { químicos }\end{array}$ & $\begin{array}{c}\text { VMP } \\
\text { (Anexo XX Portaria } \\
5 / 2017)\end{array}$ & Poço aberto & Poço fechado \\
\hline Temperatura $\left({ }^{\circ} \mathrm{C}\right)$ & --- & 27,12 & 27,64 \\
\hline $\mathrm{pH}$ & $6-9,5$ & 8,86 & 9,37 \\
\hline $\mathrm{NaCl}(\mathrm{mg} / \mathrm{L})$ & 200 & 316,73 & 382,60 \\
\hline $\begin{array}{l}\text { Condutividade } \\
\text { elétrica (uS/cm) }\end{array}$ & --- & 586,07 & 703,73 \\
\hline 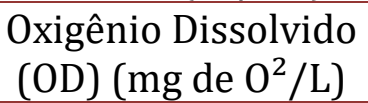 & --- & 0,47 & 2,18 \\
\hline Turbidez (uT) & $5 \mathrm{uT}$ & 6,61 & 0,44 \\
\hline $\begin{array}{c}\text { Sólidos Totais } \\
\text { Dissolvidos }(\mathrm{mg} / \mathrm{L})\end{array}$ & 500 & 353,80 & 419,20 \\
\hline $\begin{array}{l}\text { Dureza Total } \\
\left(\mathrm{mgCaCO}^{3} / \mathrm{L}\right)\end{array}$ & 300 & 266,67 & 252,53 \\
\hline $\begin{array}{c}\text { Nitrato }(\mathrm{mg} / \mathrm{L} \\
\left.\mathrm{NO}^{3} / \mathrm{L}\right)\end{array}$ & 10 & 1,58 & 1,68 \\
\hline $\begin{array}{c}\text { Nitrito }(\mathrm{mg} / \mathrm{L} \\
\left.\mathrm{NO}^{2} / \mathrm{L}\right)\end{array}$ & 1 & 0,29 & 0,05 \\
\hline $\begin{array}{c}\text { Alcalidade Total } \\
\left(\mathrm{mgCaCO}^{3} / \mathrm{L}\right)\end{array}$ & --- & 243,33 & 253,60 \\
\hline
\end{tabular}

Fonte: Autores

As análises mostraram valores médios para temperatura da água de 27,12 ํㅡ e $27,64 \stackrel{\circ}{ } \mathrm{C}$ para o poço aberto quanto para o fechado, respectivamente. Não existe na legislação brasileira padrão de potabilidade para este parâmetro. Entretanto, os valores são similares aos encontrados por Medeiros e Dourado (2010) em um estudo de águas subterrâneas na região em estudo.

Os valores de pH das águas subterrâneas dos poços aberto e fechado no assentamento Palmares apresentaram ligeiramente alcalinos. $0 \mathrm{pH}$ médio foram (8.8) e (9.4), respectivamente. valores médios dentro do limite máximo estabelecido pelo Anexo XX da Portaria ${ }^{\circ}$ 5/2017 do MS. Diferente dos resultados encontrados por Ana (2015), onde o pH variou entre 4,3 mg /L e 8,6mg/L, com valor médio de $7 \mathrm{mg} / \mathrm{L}$, indicando águas com tendência à acidez nessa região.

A variação média dos valores de salinidade foi de 316,73 mg NaCl /L para poço aberto e $382,60 \mathrm{mg} / \mathrm{L}$ de $\mathrm{NaCl}$ para poço fechado. Os valores altos da concentração de 
$\mathrm{NaCl}$, reflete também nos altos valores de condutividade elétrica encontrados. Observase que os valores obtidos tanto para poço aberto quanto para o poço fechado estão acima do Valor Máximo Permitido (VMP) que é de $200 \mathrm{mg} \mathrm{NaCl} / \mathrm{L}$ estabelecido pela Portaria de Consolidação n 5/2017 do MS (BRASIL, 2021).

De uma maneira geral, os valores de condutividade elétrica foram relativamente altos nos dois poços estudados. Valores mais altos de condutividade elétrica foram registrados no poço fechado quando comparados com o poço aberto. Nesse local, os valores médios de condutividade atingiram 703,73 mS/cm, em época seca. Isto está associado à alta concentração de minerais na água relacionada à decomposição, a compostos dissolvidos e à presença de íons. Em geral, considera-se que, quanto mais poluídas estiverem as águas, maior será a condutividade. No poço aberto, os valores estiveram próximos ao do poço fechado. Não existe um referencial para água potável na Portaria no 5/2017 do MS para este parâmetro.

0 ambiente mostrou-se relativamente mal oxigenado, com uma concentração média de oxigênio dissolvido de $0,47 \mathrm{mg} \mathrm{02/L} \mathrm{02/L} \mathrm{no} \mathrm{poço} \mathrm{aberto} \mathrm{e} \mathrm{2,18} \mathrm{mg/L} \mathrm{no} \mathrm{poço}$ fechado. Estas concentrações além de evidenciarem mal oxigenação, refletem alta concentração de matéria orgânica, visto que a oxidação da matéria orgânica consome oxigênio.

0 maior valor médio observado de STD foi de 419,20mg/L (poço fechado) e o menor de 353,16 mg/L (poço aberto). Em época seca (set - out/17), nos dois poços avaliados no assentamento Palmares, os valores registrados de STD foram maiores que $300 \mathrm{mg} / \mathrm{L}$. Não existe um padrão de qualidade de água para a concentração de STD na legislação brasileira. Alguns autores consideram que "águas claras são aquelas com teores menores que 20,0 mg/L". Valores acima de 150,0 mg/L poderiam causar preocupações em termos de qualidade a água. Nenhuma das amostras analisadas ultrapassou o valor máximo de $500 \mathrm{mg} / \mathrm{L}$ estabelecido pela Portaria nํ․ 5/2017 do Ministério da saúde.

Observa-se que os valores médios de turbidez foram muito baixos para poço fechado $(0,44 \mathrm{uT})$, embora que para poço aberto o valor médio foi um pouco maior de 6,61 uT. Quando comparado com os padrões de potabilidade estabelecidos pelo Anexo XX da Portaria de Consolidação nº 5/2017 do MS, verifica-se que apenas para o poço 
aberto o resultado do valor médio de turbidez encontra-se acima dos padrões permitidos para consumo humano ( $5 \mathrm{uT}$ ).

Concentrações de nitrato maiores que $10 \mathrm{mg}$ NO2-/L (Limite Máximo Permitido pela legislação vigente), não foram registradas em nenhum dos poços amostrados. 0 maior valor ocorreu no poço fechado (1,68 mg NO2-/L) durante o período seco. Este baixo valor de nitrato está relacionado com contaminações antigas e não recentes de matéria orgânica.

Os níveis de nitritos não ultrapassaram o permitido na legislação para consumo humano (1 mg/L). Foram encontrados valores médios $0,29 \mathrm{mg} / \mathrm{L}$ para poço aberto e 0,05 para poço fechado, valores estes abaixo do limite máximo permitido pelo MS, para consumo humano. Estes baixos valores da concentração de nitrito estão relacionados com pouca contaminação por esgoto ou matéria orgânica, principalmente recente.

A média dos valores de dureza total (magnésio + cálcio) para as amostras estudadas nos poços aberto e fechado foram relativamente altas, 266,67 mgCaCO3/L e 252,53 mgCaC03/L o que classifica água moderadamente dura. A Portaria do Ministério da Saúde $n^{\circ}$ 5/2017, estabelece o VMP para dureza total de $300 \mathrm{mg} / \mathrm{L}$. Estando as amostras de acordo este estudo (BRASIL, 2021).

A alcalinidade total foi relativamente alta, expressando altas concentrações de bicarbonatos e carbonatos, assim como dos principais cátions responsáveis pela formação dos sais de cálcio e magnésio. Os valores encontrados para alcalinidade total, flutuou entre uma média de 243,33 mg CaCO3/L para poço aberto e de 253,60 mg CaCO3/L para poço fechado. Alcalinidade em concentrações moderadas não possui significado sanitário. No entanto, em níveis elevados, pode ocasionar um sabor desagradável (BRASIL, 2014).

\section{CONCLUSÃO}

As análises realizadas neste estudo demonstraram que os parâmetros físicoquímicos avaliados se apresentaram em desconformidade com o padrão de potabilidade estabelecido pelo ministério da saúde, embora essa desconformidade não tenha sido observada em todos os parâmetros estudados. Através dos resultados obtidos, pode-se verificar o quanto a falta de um sistema de abastecimento público e de qualidade pode comprometer substancialmente a saúde e a qualidade de vida de toda uma comunidade. 
Dentre os parâmetros avaliados, chama a atenção os elevados valores de salinidade $(\mathrm{NaCl})$ cujas concentrações apresentam-se acima dos valores máximos permitidos pelo Anexo XX da Portaria de Consolidação n 5/2017 do ministério da saúde.

Considerando que o recurso hídrico subterrâneo consiste na única fonte de abastecimento para as famílias do assentamento Palmares, o acompanhamento das condições ambientais e sanitárias, as análises regulares dos parâmetros de qualidade da água, bem como a correção desses parâmetros representam alternativas importantes à estrutura precária de saneamento observada no local de estudo. De qualquer modo, fica evidente a necessidade urgente de implantação de um sistema de saneamento básico que garanta o fornecimento de água tratada e a elevação do nível de esgotamento sanitário, a fim de promover a saúde, qualidade de vida e a dignidade humana das pessoas que vivem no assentamento.

\section{REFERÊNCIAS}

Associação Nacional de Águas (ANA). Conjuntura dos recursos hídricos: Informe 2014. Brasília, DF, ANA, 2015. Disponível em:

http://conjuntura.ana.gov.br/docs/conj2014_inf.pdf. Acesso: 29 AGO 2017. anvisa.gov.br/e-legis/> Acesso em 20 out. 2017.

BERTOLO, Reginaldo Antonio; HIRATA, Ricardo; JUNIOR, Osvaldo Aly. Método de Valoração da Água Subterrânea Impactada por Atividades Contaminantes no Estado de São Paulo. Águas Subterrâneas, v. 33, n. 3, p. 303-313, 2019.

BRASIL. Fundação Nacional de Saúde. Manual de cloração de água em pequenas comunidades: utilizando o clorador simplificado desenvolvido pela FUNASA. FUNASA: Brasília-DF. 2014.

BRASIL. Portaria de Consolidação n 5 de 28 de setembro de 2017. Dispõe sobre os procedimentos de controle e de vigilância da qualidade da água para consumo humano e seupadrão de potabilidade. Ministério da Saúde. Consolidação das normas sobre as ações e osserviços de saúde do Sistema Único de Saúde. Brasília. DF, 432p. 2017. Disponível em: https://bvsms.saude.gov.br/bvs/saudelegis/gm/2017/prc0005_03_10_ 2017 .html\#CAPITULOVSECII>. Acesso 10 Ago 2021.

GOBIRA, Carla Alves; DUARTE, Stenio Fernando Pimentel. Qualidade da água do Rio Ribeirão das Pedras e a água tratada para consumo no Município de Mata Verde-MG: Uma Análise Comparativa dos Fatores Físicos-Químicos e Microbiológicos. ID on line REVISTADE PSICOLOGIA, v. 12, n. 40, p. 1082-1092, 2018. 
MEDEIROS, Gessica Hashimoto; DOURADO, Joseano Carvalho. ANÁLISE DA POTABILIDADE DA ÁGUA SUBTERRÂNEA DA BACIA DO RIBEIRÃO SÃO JOÃO, MUNICÍPIOS DE PALMAS, PORTO NACIONAL E MONTE DO CARMO, TOCANTINS. Águas Subterrâneas, 2010.

MIRLEAN, N. et al.; O Impacto Industrial Na Composição Química Das Águas Subterrâneas Com Enfoque De Consumo Humano. Rio Grande, RS. Química Nova, v. 28, n. 5, p.788-791, 2005. 


\section{Capítulo 5}

Malária x meio ambiente: Percepção dos pacientes infectados na região central do município de Araguatins, Tocantins.

\section{Tárcila Cristina Cunha Cavalcante \\ Lílian Natália Ferreira de Lima}

Dennis Gonçalves Novais

Marcia Guelma Santos Belfort

Karla Vanessa Morais Lima
Antônio Silva Machado

Francisco Alves Lima Junior

Jonathan Fernandes da Silva

Cristina Limeira Leite

Dhonnel Oliveira da Silva

Resumo: 0 presente trabalho teve por objetivo analisar a relação entre o meio ambiente e os índices de malária, baseando-se no conhecimento dos pacientes infectados pela patologia no ano de 2017, no centro de Araguatins, Tocantins. Para tal, foi realizada uma pesquisa quanti-qualitativa com coleta e análise de dados, por meio de pesquisa de campo. Os dados primários foram coletados por meio do SIVEP- Malária, fornecidos pela coordenação de endemias do município e posteriormente por meio de formulário semiestruturado contendo 20 questões abertas e fechadas, ao qual foi respondido por 17 participantes infectados na região central. Verificou- se que $88 \%$ residem em casas de alvenaria, $41 \%$ em área endêmica. Pacientes recidivos de malária foram 53\%. Os motivos de acionamento da vigilância $88 \%$ foram por água parada, em maioria residem próximo a rios (como Taquari e Araguaia), $76 \%$ reconhecem os principais sintomas da malária (Febre, calafrio e cefaleia), no entanto, ainda tem um déficit no conhecimento acerca de processos simples da doença, como: transmissão, o vetor, seu processo de reprodução e sua relação com o ambiente. Espera-se, então, conscientizar os profissionais da saúde e gestores do município para que busquem medidas que minimizem os fatores de risco.

Palavras-chave: Malária; Meio Ambiente; Pacientes Infectados. 


\section{INTRODUÇÃO}

A malaria humana é uma patologia parasitária, infecciosa, considerada um dos principais problemas de saúde pública no mundo. Causada por protozoários do gênero Plasmodium e transmitida pela picada da fêmea infectada do mosquito Anopheles, sendo mais presente em países de clima tropical e subtropical (BRASIL, 2010).

De acordo com a Organização Pan-Americana de Saúde (OPAS), a nível mundial, 3,2 bilhões de pessoas correm risco de serem infectadas por malária, o que corresponde a quase metade da população mundial. Além disso, no ano de 2015, cerca de 95 países e territórios notificaram transmissão da malária (OPAS, 2016).

No Brasil, o maior número de casos está registrado na Região Amazônica com um total de $169.570(94,9 \%)$ dos 178.613 casos notificados em todo território nacional em 2013 (BRASIL, 2015).

A variabilidade sazonal da malária pode está associada a diversos fatores climáticos e ambientais, tais como: temperatura, umidade, precipitação, padrões de uso do solo e alterações na vegetação (AMARAL, 2015).

A cidade de Araguatins está localizada no extremo norte do Tocantins e pertence a uma área da Amazônia Legal Brasileira e por isso está sujeita a surtos repentinos da doença. Além disso, percebe-se que a região é de natureza bem diversificada, onde podemos incluir diversos outros fatores de risco, como o número de criadouros, uma vez que a cidade é rodeada por rios, lagos e açudes, falta de saneamento básico com esgotos a "céu aberto", crescimento populacional desordenado, livre acesso a outros estados, falta de informação para identificação da doença e desmatamentos o que aumenta o risco de exposição ao vetor. De janeiro a julho de 2017, foram registrados 58 casos da doença no Tocantins, sendo 49 deles na cidade de Araguatins.

Esta pesquisa justificou-se pelo fato de possibilitar aos gestores e colaboradores da saúde à adequação de educação em saúde para diminuição dos casos de Malária no município, além de estimular os pacientes a saberem identificar os fatores de risco que há no ambiente em que eles vivem. 


\section{MATERIAL E MÉTODOS}

O trabalho consistiu em uma pesquisa quali-quantitativa com coleta e análise de dados, desenvolvida com 17 pacientes infectados por malária, no ano de 2017, na região central do município de Araguatins, Tocantins. Os dados primários desta pesquisa foram coletados através do Sistema de Informação de Vigilância Epidemiológica de Malária (SIVEP-MALÁRIA) e fichas de notificação. Os dados secundários foram obtidos através de um formulário contendo 20 questões fechadas e abertas, respondidos durante uma busca ativa na pesquisa de campo. Foram adotados alguns critérios de inclusão e exclusão como a disponibilidade, a aceitação e o interesse em participar da investigação, mediante assinatura do termo de consentimento que será distribuído aos mesmos.

Os dados foram tabulados e agrupados em quadros, tabelas, gráficos e figuras, utilizando o programa de planilha eletrônica, o Programa Microsoft Office Excel@ (2010) e Microsoft Office Word® (2010).

\section{RESULTADOS E DISCUSSÃO}

Durante as visitas técnicas realizadas nas residências, foi constatada a presença dos principais fatores de riscos relacionados ao ambiente. A qualidade de vida de uma sociedade pode ser demonstrada também pelas condições de habitação. Quando avaliadas as condições de moradia, constatou-se que a maioria dos participantes possuem casas de alvenaria (88\%), sendo elas: próprias (53\%), alugada (41\%) e financiada (6\%). Quanto à procedência da água os participantes que tem água encanada somaram (71\%), os que filtram a água (24\%) e os que a obtém de rios/lados/açude (6\%). Quanto ao número de pessoas que residem na casa de 1 a 3 pessoas (66\%) e mais que três (34\%).

Em consonância com os achados neste estudo, um artigo sobre a malária no Brasil, desenvolvido por Tauil et al. (1985), demonstrou que as condições das habitações está diretamente ligada a atividade do vetor. Um estudo realizado por Silva (2011) mostra que a aglomeração de pessoas em uma mesma casa é mais um fator determinante para a incidência da patologia, pois o vetor está nas proximidades da residência.

Ainda sobre o ambiente em que os participantes vivem, quando perguntados se a área em que residem seria endêmica para malária os participantes que responderam sim 
foram (41\%), não (24\%) e os que não souberam relatar (35\%). Quando perguntados sobre o acionamento dos órgãos de saúde todos tiveram uma ou mais reclamações, como água parada (88\%), lote baldio (71\%), pernilongo (29\%), lixo (59\%).

De fato, indivíduos residentes em áreas endêmicas ou não, que disponham de condições precárias de habitação, têm maior suscetibilidade para o desenvolvimento de malária e outros problemas de saúde. Segundo Parise (2009) no Brasil, toda a área que pertence a Amazônia Legal é considerada endêmica, incluindo o Tocantins, sendo então, compatível com os achados neste estudo que cita que no ano de 2017 a área em estudo foi endêmica para malária.

Todos os fatores que de certa forma alteram o ambiente natural são propícios para a proliferação do vetor. Em consonância a estes achados um estudo realizado por Pereira; Oliveira \& Maia (2017), relata que os resíduos sólidos (lixo) encontrados em vias locais estudadas e as margens de rios são fatores ambientais que contribuem para a proliferação do vetor. Outro estudo realizado pela (DIVE) Diretoria de Vigilância Epidemiológica (2018) ressalta a importância de não manter água parada com o intuito de impedir a ovoposição e nascimento de novos mosquitos da malária.

No entanto, algumas literaturas relatam que o mosquito Anopheles tem preferência por águas limpas e calmas, mas não totalmente paradas (BRASIL, 2003).

Além dos fatores citados acima, outra questão importante abordada na aplicação no formulário diz respeito às características do ambiente em que os participantes vivem. Em geral, relataram que suas residências são próximas de rios, lagos e matas:

"Morava perto de um córrego que o mesmo estava com água parada" (PARTICIPANTE 01)

"Ao fundo da minha casa passa o rio taquari que tem uma matinha nas margens, também é perto do rio Araguaia" (PARTICIPANTE 02)

“Tem de tudo, mato, brejo, rio" (PARTICIPANTE 03)

"Quando fui infectada, morava perto de um brejo" (PARTICIPANTE 04)

Isto corrobora com os achados de um estudo realizado pela USP (2013) que chegou a conclusão de que no Estado de São Paulo, a transmissão natural da malária 
ocorre principalmente em áreas de ecossistema de Mata Atlântica, onde se encontra anofelinos em alta densidade e nas áreas das bacias hidrográficas dos rios Paraná, Paranapanema e São José dos Dourados, onde há a presença de anofelinos de forma abundante.

\section{CONCLUSÃO}

A malária continua sendo uma das patologias parasitárias de maior impacto no mundo, mesmo com o desenvolvimento tecnológico e científico na atualidade. Os fatores de risco associados à incidência de malária são inúmeros, na área de estudo pode-se destacar, entre outros: desequilíbrio ambiental pela ocupação desordenada, livre acesso à estados de alta endemicidade, desmatamento e queimadas constantes, proximidade das casa à rios, lagos e açudes, pouco conhecimento sobre aspectos cruciais da doença.

Pretendeu-se com a realização desse estudo, contribuir de modo significativo para a prevenção e controle da Malária no município de Araguatins, Tocantins, além de ter um referencial que sirva de subsídio para os profissionais da saúde e gestores do Município, a fim de orientá-los sobre os fatores desencadeantes dessa patologia e incentivá-los a adoção de hábitos que melhorem o ambiente em que vivem e que são necessários para manutenção do bem-estar e qualidade de vida.

\section{REFERÊNCIAS}

AMARAL, Priscila Martins. Análise da Influência de Fatores Socioambientais e Climáticos sobre a incidência da Dengue, Malária e Tuberculose. Universidade Federal do Espírito Santo. Vitória. 2015, p. 25-31.

BRASIL. Ministério da Saúde. Secretaria de Vigilância em Saúde. Programa Nacional de Prevenção e Controle da Malária (PNCM). Brasília: Ministério da Saúde; 2003. 132 p.

BRASIL. Secretaria de Vigilância em Saúde. Doenças infecciosas e parasitárias: guia de bolso. 8. ed. rev. Brasilia, D.F.: Ministerio da Saude, 2010. 286-287 p.

BRASIL. Ministério da Saúde. Secretaria de Vigilância em Saúde. Departamento de Vigilância Epidemiológica. Guia prático de tratamento da malária no Brasil / Ministério da Saúde, Secretaria de Vigilância em Saúde, Departamento de Vigilância Epidemiológica. - Brasília : Ministério da Saúde, 2010. 36 p. 
DIVE, Diretoria de Vigilância Epidemiológica. Malária: informações para a população. Florianópolis/SC. 2018, 3 p. Disponível em:

http://www.dive.sc.gov.br/conteudos/zoonoses/ informe/InformativoMalaria.pdf

Organização Pan-Americana da Saúde (OPAS), Organização Mundial da Saúde (OMS). Malária. Brasília: OPAS; 2016. Disponível em:

https://www.paho.org/bra/index.php?option=com_content\&view=article\&id=5287:mal aria-2\&Itemid=875. Acesso em: 20/05/2019.

PARISE, Éldi Vendrame. Malária grave em Palmas, Estado do Tocantins: relato de caso. Revista da Sociedade Brasileira de Medicina Tropical, [s.l.], v. 42, n. 4, p.463-468, ago. 2009. FapUNIFESP (SciELO).

SILVA, Natal Santos da. Epidemiologia da malária: incidência, distribuição espacial e fatores de risco em uma coorte rural Amazônica. Tese: Universidade de São Paulo, São Paulo, v. 1, n. 1, p.45-332, abr. 2011.

TAUIL, Pedro; DEANE, Leônidas; SABROZA, Paulo; RIBEIRO, Cláudio. A malária no Brasil. Cadernos de Saúde Pública, [s.l.], v. 1, n. 1, p.71-111, mar. 1985. FapUNIFESP (SciELO).

USP/Faculdade de Medicina da USP. Malária. Setor de Patologias e febre Hemorrágica. São Paulo. 2013. Disponível em:

http://www2.fm.usp.br/pfh/mostrahp.php?origem=pfh\&xcod= Malaria. 


\section{Capítulo 6}

Adesão ao tratamento de pacientes adultos acometidos pela hipertensão arterial sistêmica no Brasil: Uma revisão integrativa

Andressa Flores Mendes

Lilian Natalia Ferreira de Lima

Jonathan Fernandes da Silva

Onayane dos Santos Oliveira

Francisco Alves Lima Junior
Katiane Gomes Gonçalves

Paula Cristina de Sousa Vieira

Renata de Sá Ribeiro

Érika Ferreira Tourinho

Artur de Souza Veras

Resumo: A problemática da adesão ao tratamento é complexa e envolve diversos fatores que influenciam neste processo. Os profissionais de saúde, para desempenhar medidas efetivas, com propostas e implementação de ações fundamentadas nas necessidades dos indivíduos com HAS, precisam conhecer os usuários e identificar os fatores que interferem na adesão ao tratamento, constatar esses fatores é fundamental para a investigação do seu impacto nos desfechos clínicos. O estudo tem como objetivo identificar os fatores que interferem no processo de adesão ao tratamento da HAS na população adulta do Brasil. Consiste em uma pesquisa bibliográfica de abordagem qualitativa com a utilização do método revisão integrativa, a busca foi realizada a partir de consulta de artigos científicos originais e de pesquisa publicados entre os anos $2015 \mathrm{e}$ 2021. 0 processo de seleção nas bases de dados resultou em 6 artigos para esta revisão a partir dos critérios de elegibilidade. Os resultados obtidos demostraram que os fatores que interferem no processo de adesão ao tratamento da HAS são complexos, multifatoriais e envolve ainda aspectos agregados ao reconhecimento e à aceitação das condições de saúde do indivíduo. Os principais fatores que dificultam a adesão ao tratamento da HAS encontradas no estudo foram a falta de conhecimento do paciente hipertenso sobre a sua patologia, os pacientes não seguirem as recomendações de uso da medicação, esquecimento, nível de confiança entre profissional e paciente, acesso aos serviços de saúde e condições socioeconômicas.

Palavras-chave: Hipertensão Arterial Sistêmica, Adesão ao tratamento, Saúde Pública. 


\section{INTRODUÇÃO}

As doenças crônicas não transmissíveis (DCNT) é apontada como um dos problemas de saúde pública mais críticos e crescente em todo o mundo e levam a óbito a cada ano, cerca de 41 milhões de pessoas, o que corresponde mundialmente cerca de $71 \%$ de todas as mortes (OPAS, 2018).

Dentre as DCNT mais comuns, encontra-se a hipertensão arterial sistêmica (HAS), essa doença é definida como uma entidade clínica multifatorial que depende de condições genéticas, ambientais e sociais, sendo evidenciada por níveis tensionais elevados $\geq 140$ e/ou $90 \mathrm{mmHg}$, com elevada prevalência e baixas taxas de controle. Essa patologia mantém associação independente com eventos como morte súbita, acidente vascular encefálico (AVE), infarto agudo do miocárdio (IAM), insuficiência cardíaca (IC), doença arterial periférica (DAP) e doença renal crônica (DRC), fatal e não fatal. (BARROSO, 2021).

A HAS afeta 1 bilhão de pessoas em todo o mundo, o que gera como consequência inúmeras complicações significativas para a saúde (BARROS; FILHO, JÚNIOR, 2020). Segundo o Ministério da Saúde as mortes por HAS no Brasil vêm crescendo progressivamente a cada ano. No ano de 2015, 47.288 óbitos foram registrados, em 2019, esse número saltou para 53.022 óbitos. De acordo com o Vigitel Brasil 2019, a frequência de diagnóstico médico de hipertensão entre as 27 capitais brasileiras foi de 24,5\% (BRASIL, 2021).

Dentre as medidas de enfrentamento para a Hipertensão, encontra-se: os tratamentos não farmacológicos e o farmacológico. 0 tratamento não farmacológico é fundamental, e, envolve mudanças no estilo de vida que devem ser incorporadas no cotidiano: adoção de um padrão alimentar saudável, redução de sódio, controle do peso, a prática de exercício físico, abandono do tabagismo e etilismo, entre outros. Concomitante a ele, ainda pode-se fazer necessário no caso de alguns pacientes, o tratamento farmacológico. Um grande desafio para as equipes da Atenção Primária à Saúde (APS) é iniciar o tratamento dos casos diagnosticados e manter o acompanhamento regular dessas pessoas instruindo-as à adesão ao tratamento medicamentoso e não medicamentoso (PARANÁ, 2019). 
A problemática da adesão ao tratamento é complexa e envolve diversos fatores que influenciam neste processo. Apesar de várias medidas preventivas e de controle se demostrarem eficazes/efetivas, inclusive as farmacológicas, a hipertensão continuará, por décadas, correspondendo um dos maiores desafios à saúde e gerando alto custo para os indivíduos e a sociedade (SANTOS, 2011).

Os profissionais de saúde, para desempenhar medidas efetivas, com propostas e implementação de ações fundamentadas nas necessidades dos indivíduos com HAS, precisam conhecer os usuários e identificar os fatores que interferem na adesão ao tratamento, constatar esses fatores é fundamental para a investigação do seu impacto nos desfechos clínicos, visando desempenhar ações e serviços de promoção a saúde. Nesse contexto, este estudo foi desenvolvido com o objetivo de identificar os fatores que interferem no processo de adesão ao tratamento da HAS na população adulta do Brasil.

\section{2, METODOLOGIA}

Este estudo consiste em uma pesquisa bibliográfica de abordagem qualitativa com a utilização do método revisão integrativa.

A abordagem qualitativa valoriza a descrição e a explicação dos fenômenos estudados de forma coerente (CYRIACO et al., 2017). A fase analítica dos dados qualitativos visa estabelecer uma melhor compreensão do estudo, confirmar ou não os pressupostos da pesquisa e responder às questões formuladas, ampliando assim o conhecimento acerca do tema investigado (TAQUETTE, 2016).

0 método revisão integrativa por sua vez permite investigar, ponderar e sintetizar as evidências disponíveis sobre determinado tema (TEIXEIRA et al, 2013). A revisão integrativa fundamentada na necessidade de amparar uma prática assistencial baseada em evidências científicas tem sido mencionada como ferramenta imprescindível no campo da saúde, posto que, condensa as pesquisas disponíveis sobre a temática em estudo e direciona a prática baseando-se em conhecimento cientifico (SOUSA; SILVA; CARVALHO, 2010).

A busca foi realizada a partir de consulta de artigos científicos originais e de pesquisa publicados entre os anos 2015 e 2021, indexados nas Bases de Dados da Biblioteca Virtual em Saúde/ BIREME (BVS), Base de Dados em Enfermagem (BDENF), Literatura Latino- Americana e do Caribe em Ciências da Saúde (LILACS) e Medical 
Literature Analysis and Retrieval System Online (MEDLINE). Os dados foram levantados durante o mês de maio de 2021, utilizando os descritores em Ciências da Saúde (DeCS): "Hipertensão Arterial”, “Adesão ao tratamento", combinados da expressão booleana AND.

Para a seleção dos artigos, foram adotados os seguintes critérios de inclusão: artigos ou dissertações disponíveis gratuitamente, que abordassem a temática envolvida na revisão, textos completos, artigos publicados em português, com recorte temporal entre 2015 e 2021, com objetivo de obter as evidências mais atuais possíveis. Os critérios de exclusão: artigos que não estivessem disponíveis na forma gratuita, artigos incompletos e que não atenderam aos objetivos do estudo, artigos repetidos e publicações que antecedem o período cronológico estabelecido.

Foram extraídas informações dos artigos e organizadas de acordo com os temas afins, onde foi observado o título, ano, autor, base de dados, objetivos, metodologia, resultados e as considerações finais. Foi realizada a leitura dos títulos e resumos onde foram identificados os artigos que contemplam e retratam os fatores relacionados à temática. Foram verificados a disponibilidade do texto na íntegra, após a finalização da leitura, foram extraídas informações utilizando um instrumento de análise com o objetivo de organizar as informações em forma de banco de dados contemplando: nome do artigo, ano, nome do autor, resultados e considerações finais de cada um dos artigos.

\section{RESULTADOS E DISCUSSÕES}

0 processo de seleção nas bases de dados, inicialmente, identificou um total de 141 artigos (40 na BDENF, 78 na LILACS e 23 na MEDLINE), que após a leitura minuciosa dos manuscritos e da aplicação dos critérios de exclusão e inclusão, resultaram em 6 artigos para esta revisão a partir dos critérios de elegibilidade, demostrado no Quadro 1. 
Quadro 1. Instrumento de coleta de dados: Sinopse dos artigos encontrados: título, ano, autor e bases de dados

\begin{tabular}{|c|c|c|c|c|}
\hline № & Título & Ano & Autor & Base de dados \\
\hline 1 & $\begin{array}{l}\text { Estudo comparativo entre } \\
\text { diferentes métodos de } \\
\text { adesão ao tratamento em } \\
\text { pacientes hipertensos }\end{array}$ & 2015 & ROCHA; e al & LILACS \\
\hline 2 & $\begin{array}{l}\text { O enfermeiro e a questão da } \\
\text { adesão do paciente ao } \\
\text { tratamento da hipertensão } \\
\text { arterial sistêmica }\end{array}$ & 2019 & $\begin{array}{c}\text { SALLES; et } \\
\text { al }\end{array}$ & BDENF \\
\hline 3 & $\begin{array}{l}\text { Baixa adesão terapêutica } \\
\text { em hipertensão arterial } \\
\text { sistêmica: prevalência e } \\
\text { fatores associados na } \\
\text { atenção básica à saúde }\end{array}$ & 2019 & TOSTA; et al & LILACS \\
\hline 4 & $\begin{array}{lr}\text { Adesão ao tratamento } \\
\text { medicamentoso } & \text { de adultos } \\
\text { autorreferidos } & \text { com } \\
\text { diagnóstico de hipertensão }\end{array}$ & 2020 & $\begin{array}{l}\text { DA MATA; } \\
\text { FILHO, } \\
\text { CESARINO }\end{array}$ & LILACS \\
\hline 5 & $\begin{array}{l}\text { Percepção de pessoas com } \\
\text { hipertensão arterial sobre } \\
\text { aspectos que influenciam a } \\
\text { adesão ao tratamento }\end{array}$ & 2021 & $\begin{array}{l}\text { DE } \\
\text { OLIVEIRA } \\
\text { MIRANDA; } \\
\text { et al } \\
\end{array}$ & BDENF \\
\hline 6 & $\begin{array}{l}\text { Fatores relacionados à } \\
\text { adesão ao tratamento anti- } \\
\text { hipertensivo: } \\
\text { fundamentação a partir da } \\
\text { teoria de Imogene King }\end{array}$ & 2021 & $\begin{array}{l}\text { OLIVEIRA; } \\
\text { et al }\end{array}$ & BDENF \\
\hline
\end{tabular}

Fonte: Elaborado pelos autores.

Dos 6 estudos selecionados foram incluídos os objetivos, metodologia, resultados e as considerações finais. A síntese dos artigos incluídos na revisão apresenta-se a seguir: 


\section{Objetivo}

\section{ARTIGO 1}

Comparar três instrumentos de avaliação de adesão ao tratamento da hipertensão arterial, considerando as taxas encontradas e o controle da pressão arterial. Verificar a associação da adesão ao tratamento com variáveis sociodemográficas e clínicas dos pacientes estudados.

\section{Metodologia}

Estudo transversal com 502 pessoas usuárias da Estratégia Saúde da Família, em São Luís, MA. Para avaliar a adesão, utilizados os testes: Morisky-Green (TMG), adesão a medicamentos- Qualiaids (QAM-Q) e o Haynes. Para verificar a associação da adesão ao tratamento com as variáveis sociodemográficas e clínicas, utilizados os testes exatos de Fisher ou qui- quadrado.

\section{Resultado}

A prevalência de não adesão pelo TMG foi 29,28\%, 60,16\% pelo QAM-Q e 13,15\% pelo questionário Haynes. Os testes Haynes-QAM-Q (kappa=80,68\%) apresentaram concordância substancial; o QAM-Q-Morisky (kappa=48,61\%) e o Morisky-Haynes (kappa=55,58\%), concordância moderada. As variáveis tabagismo e comparecimento aos retornos associaram-se nos três testes com a não adesão ao tratamento.

\section{Considerações Finais}

Os testes avaliados apresentaram boa concordância. A não adesão foi elevada pelo QAM-Q, e baixa pelos TMG e Haynes. Considerando o controle da pressão arterial, o QAM-Q e o Haynes apresentaram significância estatística; o QAM-Q identificou o maior número de indivíduos com pressão não controlada dentre os que não aderem. As variáveis tabagismo e comparecer aos retornos.

\section{Objetivo}

\section{ARTIGO 2}

Identificar os recursos utilizados pelo enfermeiro da estratégia saúde da família (ESF) para estimular a adesão do paciente ao tratamento da Hipertensão Arterial Sistêmica.

\section{Metodologia}

Abordagem qualitativa. 0 projeto foi aprovado por Comitê de Ética emPesquisa. A coleta de dados ocorreu no período de abril a agosto de 2017, por meio de entrevista semiestruturada com 10 enfermeiros atuantes emunidades de ESFlocalizadas no Estado do Rio de Janeiro. Os depoimentos dos sujeitos foram submetidos à análise de conteúdo de Bardin.

\section{Resultado}

Os enfermeiros realizam consultas de enfermagem garantindo a adesão dos participantes em atividades educativas de grupo, como palestras e orientações de enfermagem.

\section{Considerações Finais}

O sistema utilizado na adesão ao tratamento é similar entre as unidades de ESF mantendo um padrão preconizado pela literatura. 


\section{Objetivo}

\section{ARTIGO 3}

Estimar a associação entre fatores sociodemográficos, culturais e de estilo de vida com a adesão terapêutica de hipertensos.

\section{Metodologia}

Realizou-se um estudo transversal com usuários hipertensos que usavam medicação para controle dos níveis pressóricos e buscavam atendimento em unidades de atenção básica em um distrito sanitário da cidade do Salvador, Bahia. Foram incluídos os que tinham idade maior que 18 anos e excluídos os que tinham alteração cognitiva e também mulheres com hipertensão gestacional. A magnitude da associação entre as variáveis estudadas e a adesão terapêutica foi estimada pelo cálculo da razão de chances (Odds Ratio, OR), adotando-se o intervalo de confiança a 95\% (IC95\%).

\section{Resultado}

A amostra foi composta com 185 hipertensos e a prevalência de não adesão ao tratamento foi de $68,1 \%$. Os fatores associados com a não adesão terapêutica foram situação conjugal solteiro, separado, viúvo (OR=2,23; IC95\% $1,04 \quad$ - 4,47), não alteração dos hábitos alimentares (OR=2,51; IC95\% 1,12 - 5,59), assim como faltar às consultas (OR=4,20; IC95\% 1,16 - 15,18) e entender bem tudo que é dito em uma consulta (OR=0,60; IC95\% 0,38-0,95).

\section{Considerações Finais}

Grande parte dos hipertensos não apresentou adesão terapêutica, e os fatores associados são passíveis de modificação por meio de tecnologias leves e investimentos na qualidade da atenção primária à saúde. Devem ser encorajados novos estudos com desenhos longitudinais que possam identificar as causas da não adesão.

Objetivo

\section{ARTIGO 4}

Identificar

o nível de adesão ao tratamento medicamentos o de adultos autorreferidos com diagnóstico de hipertensão.

\section{Metodologia}

Trata-se de um estudo descritivo-transversal envolvendo 213 indivíduos autorreferidos com diagnóstico de hipertensão participantes em campanhas de hipertensão arterial realizadas em cidade do interior paulista. Os instrumentos de coleta de dados utilizados foram entrevistas semiestruturadas e questionário de Morisky e Green. Foram aplicados o teste qui-quadrado e análise de correspondência múltipla.

\section{Resultado}

A maioria dos participantes do estudo relatou não aderir ao tratamento medicamentoso (84\%). 0 sexo feminino apresentou maior adesão. As barreiras à adesão foram dificuldade para mudança de hábitos de vida, irregularidade às consultas médicas e aos horários das medicações.

\section{Considerações Finais}

A adesão ao tratamento medicamentoso constitui-se de um processo complexo e 
multifatorial que merece atenção especial da equipe multiprofissional em saúde com o objetivo de aumentar as taxas de adesão e a qualidade de vida dos indivíduos.

Objetivo

\section{ARTIGO 5}

Descrever a percepção de pessoas com hipertensão arterial sobre os aspectos que facilitam e dificultam a adesão ao tratamento.

\section{Metodologia}

Estudo

qualitativo descritivo desenvolvido com 16 pessoas atendidas em consultas de enfermagem. Realizaram- se entrevistas com roteiro semiestruturado e utilizou- se a técnica de análise de conteúdo. Os dados foram coletados entre os meses de janeiro e agosto de 2017.

\section{Resultado}

Observou-se que ter força de vontade, apoio familiar e multiprofissional, conhecimento sobre a patologia e formas de prevenção e medo da morte facilitou a adesão; por outro lado, pouco conhecimento, preguiça, falta de infraestrutura urbana e condições climáticas, hábito de consumir alimentos não saudáveis, bebidas alcoólicas e tabaco, custo do tratamento e esquecimento de tomar a

medicação dificultaram a adesão.

\section{Considerações Finais}

O tratamento da hipertensão acarreta mudanças na dinâmica da vida para as quais é fundamental ter força de vontade, apoio familiar e profissional, além de superar hábitos não saudáveis.

\section{Objetivo}

\section{ARTIGO 6}

Conhecer as percepções de usuários hipertensos diante do tratamento anti-hipertensivo, relacionando-as com os conceitos do sistema interpessoal da Teoria do Alcance de Metas de Imogene King.

\section{Metodologia}

Estudo descritivo e exploratório, com abordagem qualitativa, realizado com 10 usuários hipertensos. Foram realizadas entrevistas semiestruturadas para a coleta dos dados e utilizou-se a Análise de Conteúdo Temática proposta por Minayo para análise do material.

\section{Resultado}

Foi possível identificar dois eixos temáticos Viver com Hipertensão Arterial Sistêmica; Dificuldades diante da adesão ao tratamento anti-hipertensivo.

\section{Considerações Finais}

A necessidade de uso contínuo da medicação, mudanças no cotidiano dos indivíduos e o desconhecimento em relação à patologia, são fatores que podem influenciar a adesão ao tratamento anti-hipertensivo. Ressalta-se que a relação entre o enfermeiro e o paciente é compreendida como aspecto que contribui para a terapêutica. 
Os artigos analisados nessa revisão buscaram identificar os fatores que interferem na adesão ao tratamento do paciente com hipertensão.

A não adesão ao tratamento da HAS, tanto em relação às modificações do estilo de vidaquanto medicamentosa, influencia diretamente no controle da PA. Além disso, o fato da hipertensão ser uma patologia muita das vezes assintomática e por ser crônica, auxilia fortemente para baixa adesão ao tratamento (ROCHA et al., 2015).

A adesão ao tratamento envolve várias questões, como mudanças no estilo de vida, crenças, conhecimento acerca da doença, condições socioeconômicas, além de acesso aos serviços de saúde e a medicação (De Oliveira Miranda et al., 2021). Todos os fatores devem ser trabalhados em concomitância para que ocorra o sucesso no tratamento do paciente.

É imprescindível que os profissionais procurem identificar quais são as variáveis associadas a não adesão do tratamento, do abandono e do uso incorreto da medicação. A etapa inicial é garantir ao paciente o conhecimento sobre sua patologia. 0 conhecimento leva o paciente a uma maior percepção da gravidade e do risco de complicações, assim, favorece a promoção da saúde, com mudanças no estilo de vida, escolhas mais conscientes e saudáveis, e consequentemente, a redução do risco cardiovascular (DE OLIVEIRA MIRANDA et al., 2021

TOSTA et al (2019) em seu estudo apontou que, em geral, é estimado que dos usuários que realizam tratamento medicamentoso da HA menos de $80 \%$ da população segue corretamente as recomendações de uso. 0 paciente conhecer e entender a gravidade da sua doença, contribui significativamente na compreensão do paciente em realizar o tratamento medicamentoso e não medicamentoso. Fatores como a presença de comorbidades e o paciente não compreender o que é dito nas consultas com profissionais afeta o êxito do tratamento.

Outro fator determinante destacado no estudo de Oliveira et al (2021) é a escassez de medicação anti-hipertensiva na unidade de saúde, essa realidade pode se tornar uma grande barreira, visto que muitos pacientes não têm a condição financeira para adquirir essas medicações, e geralmente opta pelo abandono do tratamento. Além disso, a utilização de vários fármacos para o tratamento da patologia e de comorbidades associadas também podem interferir diretamente nesse processo. 
Em seu estudo De Oliveira Miranda et al (2021) identificou esquecimento, custo dos medicamentos, déficit visual e os efeitos indesejados do tratamento como as principais dificuldades citadas por pacientes hipertensos. Nesse sentido pode-se afirmar que o acesso aos serviços de saúde por si só não garante bons resultados. Os profissionais de saúde devem juntamente com os pacientes e seus familiares buscar estratégias que auxiliem o paciente na adesão do tratamento tanto medicamentoso quanto não medicamentoso, ademais, também realizar visitas domiciliares, que além de acompanhar o paciente, poderá identificar demais fatores que possam interferir nessa adesão.

O avanço da idade demostrou-se como um importante fator para não adesão do tratamento. Esse achado se justifica pela vulnerabilidade dessa faixa etária, o declínio das capacidades mentais, cognitivas e físicas. Dessa forma, demostra-se de suma importância o apoio e a ajuda familiar, além de estratégias focadas em ações multidisciplinares, informando e empoderando os pacientes (DA MATA; FILHO; CESARINO, 2021).

A relação do profissional de saúde com o paciente demostra-se como uma ferramenta promissora para o desenvolvimento da prática Inter profissional, o que permite um melhor acolhimento para o paciente, tendo como base a comunicação, que é primordial para a promoção da saúde do usuário (OLIVEIRA et al, 2021). A aproximação junto aos pacientes é relevante para maior adesão à terapia, principalmente pelo fato de a HAS ser uma doença crônico-degenerativa de tratamento prolongado. É preciso estimular hábitos e atitudes que irão melhorar a qualidade de vida dos pacientes, encontrar estratégias que maximizem o envolvimento das pessoas com as mudanças de hábitos necessárias a uma vida saudável (SALLES et al, 2019).

\section{CONSIDERAÇÕES FINAIS}

Os fatores que interferem no processo de adesão ao tratamento da HAS são complexos, multifatoriais e envolve ainda aspectos agregados ao reconhecimento e à aceitação das condições de saúde do indivíduo. Os principais fatores que dificultam a adesão ao tratamento da HAS encontradas no estudo foram a falta de conhecimento do paciente hipertenso sobre a sua patologia, os pacientes não seguirem as recomendações 
de uso da medicação, esquecimento, nível de confiança entre profissional e paciente, acesso aos serviços de saúde e condições socioeconômicas.

Considerando que a intervenção terapêutica da HAS acarreta uma redução significativa da morbimortalidade por DCV, se demostra de suma importância conhecer os fatores que interferem no processo de adesão ao tratamento da HAS, além de identificar grupos mais vulneráveis, buscando contribuir para criação e/ou efetivação de políticas de saúde mais equânimes. É perceptível ainda a necessidade de acompanhamento de redes de atenção à saúde, através de um acompanhamento multiprofissional sistemático e periódico, garantindo a integralidade do cuidado, havendo ainda a necessidade de conhecer a realidade de cada paciente, facilitando a efetivação de medidas que busquem minimizar e controlar a HAS e consequentemente a diminuição da prevalência de doenças relacionadas.

O conhecimento acerca dos fatores que interferem no processo de adesão ao tratamento da hipertensão, permite efetivar medidas educativas e assistenciais, visando a prevenção e o controle dessa patologia. Além disso, medidas como estabelecer uma relação com o paciente com ênfase no diálogo e no envolvimento da família no tratamento, favorece o conhecimento do paciente acerca da sua patologia e consequentemente no aumento da adesão ao tratamento. Faz-se necessário ainda destacar a necessidade de políticas de promoção a saúde mais desenvolvidas, que visem minimizar as desigualdades socioeconômicas e a prevalência de HAS.

\section{REFERÊNCIAS}

BARROS, Gabriel Martins; FILHO, João Batista Raposo Mazullo; JÚNIOR, Aírton Conde Mendes. Considerações sobre a relação entre a hipertensão e o prognóstico da COVID19. Journal of Health \& Biological Sciences, v. 8, n. 1, p. 1-3, 2020. Disponível em: https://periodicos.unichristus.edu.br/jhbs/article/view/3250. Acesso em:18/09/2021.

BARROSO, Weimar Kunz Sebba et al. Diretrizes Brasileiras de Hipertensão Arterial2020. Arquivos Brasileiros de Cardiologia, v. 116, p. 516-658, 2021. Disponível em: http://departamentos.cardiol.br/sbc-dha/profissional/pdf/Diretriz-HAS-2020.pdf. Acesso em:20/05/2021.

BRASIL. Ministério da Saúde. Hipertensão arterial: hábitos saudáveis ajudam na prevenção e no controle da doença. 2021. Disponível em: https://www.gov.br/saude/pt-br/assuntos/noticias/hipertensao-arterial-habitossaudaveis-ajudam-na-prevencao-e-no-controle-da-doenca. Acesso em:18/09/2021. 
CYRIACO, Aline Figueiredo Falcão et al. Pesquisa qualitativa: conceitos importantes e breve revisão de sua aplicação à geriatria/gerontologia. 2017. Disponível em: https://cdn.publisher.gn1.link/ggaging.com/pdf/v11n1a02.pdf. Acesso em: $15 / 06 / 2021$.

DA MATA, Jéssica Gabriela Figueiredo; DE GODOI FILHO, Marcelo Brito; CESARINO, Claudia Bernardi. Adesão ao tratamento medicamentoso de adultos autorreferidos com diagnóstico de hipertensão. Saúde e Pesquisa, v. 13, n. 1, 2020. Disponível em: https://pesquisa.bvsalud.org/portal/resource/pt/biblio-1052894. Acesso em: 20/05/2021.

DE OLIVEIRA MIRANDA, Paulo Roberto et al. Percepção de pessoas com hipertensão arterial sobre aspectos que influenciam a adesão ao tratamento. Revista de Enfermagem da UFSM, v. 11, p. 6, 2021. Disponível em: https://periodicos.ufsm.br/reufsm/article/view/42403/html.Acesso em 20/05/2020.

DE OLIVEIRA, Deiziane Serafim et al. Fatores relacionados à adesão ao tratamento antihipertensivo: fundamentação a partir da teoria de Imogene King. Nursing (São Paulo), v. 24, n. 276, p. 5622-5631, 2021.Disponível em:

http://revistas.mpmcomunicacao.com.br/index.php/revistanursing/article/view/1534 /1748. Acesso em: 20/09/2021.

OPAS. ORGANIZAÇÃO PAN-AMERICANA DE SAÚDE. Comissão da OMS pede ação urgente contra doenças crônicas não transmissíveis. Disponível em: https://www.paho.org/bra/index.php?option=com_content\&view=article\&id=5691:c omissao-da-oms-pede-acao-urgente-contra-doencas-cronicasnaotransmissiveis\&Itemid=839. Acesso em: 18/09/2021.

ROCHA, Tania Pavão Oliveira et al. Estudo comparativo entre diferentes métodos de adesão ao tratamento em pacientes hipertensos. Int J Cardiovasc Sci, v. 28, n. 2, p. 122 129, 2015. Disponível em: http://www.onlineijcs.org/sumario/28/pdf/v28n2a07.pdf. Acesso em: 20/05/2021.

SALLES, Anna Luisa de Oliveira et al. 0 enfermeiro e a questão da adesão do paciente ao tratamento da hipertensão arterial sistêmica. Rev. enferm. UERJ, p. e37193-e37193, 2019. Disponível em: https://pesquisa.bvsalud.org/portal/resource/pt/biblio-1005387. Acesso em: 20/05/2021.

SANTOS, Zélia Maria de Sousa Araújo. Hipertensão arterial-um problema de saúde pública. Revista Brasileira em Promoção da saúde, v. 24, n. 4, p. 285-286, 2011. Disponível em: https://periodicos.unifor.br/RBPS/article/viewFile/2083/2376. Acesso em:18/09/2021.

SOUZA, Marcela Tavares de; SILVA, Michelly Dias da; CARVALHO, Rachel de. Revisão integrativa: o que é? Como fazer isso? Einstein (São Paulo), São Paulo, v. 8, n. 1, pág. 102-106, março de 2010. Disponível em: 
http://www.scielo.br/scielo.php?script=sci_arttext\&pid=S1679$45082010000100102 \& \operatorname{lng}=\mathrm{en} \& \mathrm{nrm}=$ iso. Acesso em: 06/05/2021.

TAQUETTE, Stella R. Análise de dados de pesquisa qualitativa em saúde. In: Congresso Ibero Americano de Investigação Qualitativa, 5, 2016, Porto. Porto: CIAIQ, 2016. Disponível em:https://proceedings.ciaiq.org/index.php/ciaiq2016/article/view/790/777.Acesso em:18/09/2021.

TEIXEIRA, Elizabeth et al. Revisão integrativa da literatura passo a passo e convergências com outros métodos de revisão. Revista de Enfermagem da UFPI, v. 2, n. 5, pág. 3-7, 2013. Disponível em:

https://ojs.ufpi.br/index.php/reufpi/article/view/1457/pdf. Acesso em:18/09/2021.

TOSTA, Larissa et al. Baixa adesão terapêutica em hipertensão arterial sistêmica: prevalência e fatores associados na atenção básica à saúde. Revista Pesquisa em Fisioterapia, v. 9, n. 1, p. 45-55, 2019. Disponível em:

https://www5.bahiana.edu.br/index.php/fisioterapia/article/view/2222. Acesso em: 20/05/2021. 


\section{Capítulo 7}

O perfil sociodemográfico, hábitos de higiene e consumo dos manipuladores de alimentos das escolas públicas do município de Augustinópolis-To

Géssica Queiroz da Silva

Lilian Natália Ferreira de Lima

Luysa dos Santos Sanches

Antônio Silva Machado

Marcia Guelma Santos Belfort
Dennis Gonçalves Novais

Ricardo Henrique Paes Barreto Peixoto

Katiane Gomes Gonçalves

Paula Cristina de Sousa Vieira

Nayara Sousa de Lima

Resumo: Avaliar o perfil sociodemográfico, hábitos de higiene e consumo dos manipuladores de alimentos das escolas públicas do município de Augustinópolis -TO. É um estudo exploratório descritivo com abordagem qualitativa e enfoque quantitativo, o público alvo são os manipuladores de alimentos das escolas públicas localizado no município de Augustinópolis-TO e o instrumento de coleta de dados foi através da aplicação de formulários socioeconômico. 10 manipuladores de alimentos que atuam em 6 escolas do município de Augustinópolis-TO, sendo que 100\% é gênero feminino, com faixa etária $>50$ anos (50\%), escolaridade de ensino médio (80\%), apresentando renda de um salário mínimo (80\%), mora em domicilio próprio e de alvenaria (100\%), na zona urbana (70\%) e o número de moradores na mesma residência e 3 a 6 (50\%). Quando ao habito de higiene $100 \%$ afirmaram que higieniza as mãos, faz consumo de carne, verdura e frutas (100\%) e a higienização das frutas e a lavagem com vinagre (50\%). 0 trabalho irá contribuir para os indicadores de saúde do município de Augustinópolis-TO para que assim ofereça melhores condições sanitárias e aumentar a fiscalização da vigilância sanitária nas escolas com o intuito de diminuir o índice de contaminação e disseminação de enteroparasitoses

Palavras-chave: Alimentos, Perfil sociodemográfico dos manipuladores, Perfil dos hábitos de higiene e consumo dos manipuladores, Enteroparasitoses. 


\section{INTRODUÇÃO}

Uma alimentação saudável é indispensável para sobrevivência de qualquer pessoa, pois é essencial para o crescimento, desenvolvimento e manutenção da vida, principalmente na infância, mas também pode ser responsável pela transmissão de várias doenças. Dessa forma, a manipulação inadequada é a grande causa da contaminação dos alimentos, por isso é importante estar atento as práticas corretas de higiene pessoal e alimentícias (LEÃO RC, et al., 2018).

Dessa maneira, de acordo com Silva T0, et al. (2018) cerca de 30\% da população mundial é atingida pelas parasitoses intestinais, em países subdesenvolvidos estima-se que $90 \%$ da população seja infectada isso, por que, nas regiões mais desfavorecidas as condições de higiene pessoal, o manejo com alimentos, e as condições de trabalho dos profissionais são precárias, além do mais, os serviços de saneamento básico serem escassos, existe a falta de ações em programas de educação sanitária para a população, que agravam ainda mais esse quadro.

Nesse aspecto, para Castro IRR, et al. (2011) o termo manipulador de alimentos é dado a quaisquer indivíduos que está em contato com o produto comestível ou parte do mesmo em qualquer etapa da sua produção. Assim, segundo a Agencia Nacional de Vigilância Sanitária, resolução n 216, de 15 de setembro de 2004, os manipuladores de alimentos devem ser supervisionados e capacitados periodicamente em higiene pessoal, em manipulação higiênica dos alimentos e em doenças transmitidas por alimentos, uma vez que o objetivo é estabelecer procedimentos de Boas Práticas para serviços de alimentação nas instituições a fim de garantir as condições higiênico sanitárias do alimento preparado.

Sendo assim, é notório que as condições em que os alimentos se encontram são fundamentais para a saúde pública, uma vez que eles serão consumidos por uma coletividade, como em instituições de ensino, por isso, é muito importante que as instituições ofereçam condições de trabalho adequadas ao manipulador, oferecendo a eles sempre que necessário um treinamento especifico e a realização de exames periódicos para o controle de infecções que eles possam adquirir, uma vez que, os indivíduos contaminados são considerados uma fonte potencial de transmissão de doenças, conferindo assim, grande risco para a saúde da população (JÚNIOR AFC, et al., 2017). Assim, diante da realidade apresentada, o presente estudo buscou responder a 
problemática que tem como objetivo de avaliar o perfil sociodemográfico dos manipuladores de alimentos das escolas públicas do município de Augustinópolis -TO, para que assim, possa verificar se os mesmos estão infectados por enteroparasitos, para interromper a cadeia de transmissão, e diminuir o risco de crianças serem contaminados pela merenda escolar.

\section{MÉTODOS}

Este estudo é de caráter exploratório descritivo com abordagem qualitativa e enfoque quantitativo baseado nos critérios da Strengthening the Reporting of Observational Studies in Epidemiology (STROBE) que permite a descrição adequada de pesquisas de natureza observacional, possibilitando avaliar corretamente os pontos críticos e potenciais, diminuindo a generalização dos resultados encontrados. Dessa forma, no método de exploratório, seu objetivo é a caracterização inicial do problema, sua classificação e sua definição, ele constitui o primeiro estágio de toda pesquisa científica e possui a finalidade de proporcionar maior familiaridade com o problema e fazer um levantamento bibliográfico ou entrevistas, já na pesquisa descritiva os fatos são observados, registrados, analisados, classificados e interpretados, sem interferência do pesquisador, neste método utilizam-se técnicas padronizadas de coleta de dados, como questionário e observação sistemática (RODRIGUES WC, et al., 2007). Portanto, a abordagem qualitativa é aquela em que o investigador sempre faz alegações de conhecimentos sobretudo com base em perspectivas construtivas ou em perspectiva reivindicatória ou em ambas. Por outro lado, a abordagem quantitativa é aquela em que o investigador usa inicialmente alegações pós-positivistas para o desenvolvimento do conhecimento, ou seja, raciocínio de causa e feito e também emprega estratégias de investigação como experimentos, levantamentos e coleta de dados (CRESSWELL JW, 2010).

Dessa maneira, o público alvo foi delimitado segundo critérios de escolha das escolas públicas municipais da área urbana do município de Augustinópolis-TO, excluindo as instituições que estão localizadas na zona rural, sendo que a população estudada foram os manipuladores de alimentos que aceitarem participar do estudo através do Termo de Consentimento Livre e Esclarecido - TCLE, pois a população foi 
constituída por 10 manipuladoras de alimentos das 6 escolas públicas municipais da área urbana do município de Augustinópolis.

Nesse sentido, para proceder a análise, os dados foram dispostos em uma planilha Microsoft Excel. Posteriormente, foram analisados com a utilização do pacote estatístico Statistical Package of Social Sciences (SPSS, 26,0). Caracterizando o perfil sociodemográfico foi realizada por meio de frequência absoluta (n) e frequência relativa (\%). Assim, o teste do Qui-quadrado de Pearson foi aplicado e fim de avaliar a associação entre a faixa etária, escolaridade e renda familiar com o perfil epidemiológico e o nível de significância adotado foi de $5 \%(\mathrm{p}<0,05)$.

Portanto, este estudo foi desenvolvido mediante aprovação do Comitê de Ética em Pesquisa da Universidade Estadual do Tocantins. Seguindo os princípios éticos de acordo com a Resolução CNS no 466/12 do Ministério da Saúde que rege a realização de pesquisas envolvendo seres humanos, e que estabelece prioridade pelo respeito, pela dignidade humana e pela especial proteção devida aos participantes das pesquisas científicas, visto que a resolução propõe que toda pesquisa envolvendo seres humanos direta ou indiretamente deverá ser submetida à apreciação de um Comitê de Ética em Pesquisa sob no CAAE 15025119.8.0000.8023 e o parecer 3.503.572, este estudo buscou proteger a dignidade, e integridade da pessoa humana participante da pesquisa.

\section{RESULTADOS E DISCUSSÃO}

Dessa forma, os resultados obtidos no estudo foram apresentados em duas categorias: 1. Características do Perfil Sociodemográfico dos Manipuladores de Alimentos e a 2. Características Do Perfil Hábitos De Higiene e Consumo dos Manipuladores de Alimentos. Assim, a partir deste tópico serão divulgados, os resultados, através de literaturas relacionadas, onde os dados obtidos foram comparados a outros estudos concretizados cujos temas identificam-se, com a finalidade de alcançar os objetivos da pesquisa. Dessa forma, a tabela 1 irá apresentar os resultados da Características do Perfil Sociodemográfico dos Manipuladores de Alimentos: 
Tabela 1. Caracterização do perfil sociodemográfico $(n=10)$.

\begin{tabular}{|c|c|c|}
\hline & $\mathbf{N}$ & $\%$ \\
\hline \multicolumn{3}{|l|}{ Gênero } \\
\hline Feminino & 10 & 100,0 \\
\hline Masculino & 0 & 0,0 \\
\hline \multicolumn{3}{|l|}{ Faixa etária } \\
\hline 18 a 39 & 3 & 30,0 \\
\hline 40 a 50 & 2 & 20,0 \\
\hline$>50$ & 5 & 50,0 \\
\hline \multicolumn{3}{|l|}{ Escolaridade } \\
\hline Ensino médio & 8 & 80,0 \\
\hline Ensino superior & 2 & 20,0 \\
\hline \multicolumn{3}{|l|}{ Renda familiar } \\
\hline 1 salário mínimo & 8 & 80,0 \\
\hline 2 salários mínimos & 2 & 20,0 \\
\hline \multicolumn{3}{|l|}{ Residência } \\
\hline Rural & 3 & 30,0 \\
\hline Urbana & 7 & 70,0 \\
\hline \multicolumn{3}{|l|}{ Domicílio próprio } \\
\hline Não & 0 & 0,0 \\
\hline Sim & 10 & 100,0 \\
\hline \multicolumn{3}{|l|}{ Moradia } \\
\hline Alvenaria & 10 & 100,0 \\
\hline Outro & 0 & 0,0 \\
\hline \multicolumn{3}{|l|}{ N⿳a de moradores } \\
\hline 1 a 3 & 4 & 40,0 \\
\hline 3 a 6 & 5 & 50,0 \\
\hline mais de 6 & 1 & 10,0 \\
\hline
\end{tabular}

$\mathrm{n}$ = frequência absoluta; $\%$ = frequência relativa

Fonte: Dados da Pesquisa, 2020.

Dessa forma, nesta pesquisa foram entrevistados 10 manipuladores de alimentos que atuam em 6 escolas do município de Augustinópolis-TO. Assim, todos os participantes pertenciam ao gênero feminino (100\%) com predominância da faixa etária 
$>50$ anos representando $50 \%$ do valor total dos manipuladores. Nesse sentido, quanto ao nível escolaridade, $80 \%$ dos entrevistados teriam o ensino médio e apenas $20 \%$ possuíam ensino superior, pois segundo Lima-Costa MF e Barreto SM (2013) as parasitoses intestinais podem ser observadas com mais frequência nos indivíduos de baixa renda e com menor grau de escolaridade, uma vez que este dado também foi descrito no estudo de Santos YKA, et al. (2018) no qual, os indivíduos com maior escolaridade tinham mais conhecimento sobre o que seria uma parasitose e sobre os métodos de transmissão dessa infecção. Portanto, autores afirmam que as condições de moradia e as condições ambientais influenciam diretamente no nível de infecção parasitaria das populações, Camello JT, et al. (2016) acredita que as elevadas taxas de parasitoses intestinais em diferentes regiões do Brasil, são decorrentes das diferentes condições ambientais, de saneamento básico e socioeconômicas das populações.

Nesse aspecto, foi observado neste estudo que 100\% dos pesquisados possuem domicilio próprio e de alvenaria, sendo que 70\% reside em área urbana e 30\% em zona rural, uma vez que um estudo sobre o levantamento de parasitos intestinais nas áreas urbana e rural de Itambé do Mato Dentro-MG, os percentuais de infecção na área rural foram significativamente maiores que os da área urbana (MATI VLT; PINTO JH; MELO $A L$, 2011). Dessa maneira, em outro levantamento acerca da ocorrência de enteroparasitos em áreas rurais e urbanas do município de Campos Novos, oeste de Santa Catarina, constatou-se que 58,5\% e 30,9\% amostras de estudantes da zona rural e urbana, respectivamente, apresentaram parasitos, indicando uma elevada prevalência de parasitos na área rural (BIOLCHI LC, et al., 2015).

Portanto, quanto ao número de moradores na mesma residência $40 \%$ disseram possuir de 1 a 3, 50\% de 3 a 6 e apenas 10\% possuem mais de 6 moradores na mesma residência, estes dados revelaram que a maior parte da população entrevistada não apresentou números elevados de moradores na residência, o que pode ser visto como algo positivo levando em consideração o estudo realizado por Lopes MO (2016), no qual foi observado que as maiores prevalências de helmintíases intestinais foram registradas em indivíduos residentes em domicílios com um número maior de moradores.

Dessa maneira, a tabela 2 irá apresenta dos dados obtidos na pesquisa relacionado a Caracterização do perfil hábitos de higiene e consumo dos Manipuladores de Alimentos: 
Tabela 2. Caracterização do perfil hábitos de higiene e consumo $(n=10)$.

Higienização das mãos

Não

Sim

Consome carne

Não

Sim

\section{Consome verduras}

Não

Sim

\section{Consome frutas}

Não

Sim

\section{Higienização das frutas}

Cozinha no vapor

1

10,0

Lavagem com água corrente

4

Lavagem com vinagre
0

0,0

10

100,0
0,0

10

100,0

0

0,0

10

100,0

$\mathrm{n}=$ frequência absoluta; $\%$ = frequência relativa

Fonte: Dados da Pesquisa, 2020.

Desse modo, os hábitos de higiene adequados como a lavagem das mãos frequentemente é um importante meio de prevenção de doenças. Assim, partindo desse pressuposto, foi constatado que todos os entrevistados (100\%) relataram realizar a higienização das mãos com frequência, dado semelhante foi encontrado na pesquisa de Santos YKA, et al. (2018) sobre a presença de enteroparasitos em manipuladores de alimentos, pois na variável analisada sobre higiene também foi constatado que 100\% 
dos indivíduos lavavam as mãos com frequência. Nesse sentido, já no estudo de Silva TO, et al. (2018), mesmo não tendo encontrado relação estatística com o resultado dos exames, a maioria dos manipuladores de alimentos que informaram lavar as mãos somente as vezes, apresentaram resultados positivos no exame parasitológico.

Nesse aspecto, quanto ao consumo observou-se, que todos os entrevistados se alimentavam com frutas e verduras, sendo que a maioria dos participantes realiza a higienização dos mesmos por meio da lavagem com vinagre $50 \%$, seguidos de lavagem com água corrente $40 \%$ e somente $10 \%$ cozinha esses alimentos no vapor. Dessa maneira, segundo Barros DM, et al. (2019) os alimentos tem sido um meio importante de exposição as enteropasitoses, pois o consumo de alimentos frescos tende a aumentar os riscos de contaminação por parasitos intestinais, visto que os mesmos podem conter cistos, ovos e larvas, e além disso, em condições propícias as formas infectantes dos parasitos podem permanecer vivas por longos períodos, e além do mais, o consumo de hortaliças, principalmente na sua forma crua, é apontado como uma das principais possibilidades que o indivíduo tem de contrair alguma parasitose. Portanto, no estudo de Gregório DS, et al. (2012) apresenta que após investigar a transmissão de parasitoses através do consumo de hortaliças cruas, contaminadas por dejetos fecais e inadequadamente higienizadas, e analisar 45 amostras de hortaliças, detectou-se que aproximadamente 55\% destas continham alguma estrutura parasitária e no estudo de Melo ZFM, et al. (2011) ao analisar a contaminação parasitária de alfaces e sua relação com enteroparasitoses, encontrou 40,9\% de alfaces contaminadas por larvas e cistos de protozoários.

\section{CONCLUSÃO}

Desse modo, presente estudo demostrou a importância de identificar a ocorrência de enteroparasitoses em manipuladores de alimentos de escolas municipais, objetivando evitar que parasitas intestinais sejam transmitidos aos escolares. Assim, no estudo observou como ponto negativo que $80 \%$ dos entrevistados teriam o ensino médio e estudo apontam que as parasitoses intestinais podem ser observadas com mais frequência nos indivíduos de baixa renda e com menor grau de escolaridade, e além disso, como ponto positivo que 70\% reside em área urbana e estudos indicam uma elevada prevalência de parasitos na área rural, e além do mais, quanto ao número de 
moradores na mesma residência 40\% disseram possuir de 1 a 3, 50\% de 3 a 6 e apenas $10 \%$ possuem mais de 6 moradores na mesma residência, o que pode ser visto como algo positivo, pois as maiores prevalências de helmintíases intestinais foram registradas em indivíduos residentes em domicílios com um número maior de moradores. Desse modo, quando os hábitos de higiene adequados como a lavagem das mãos $100 \%$, visto que, a lavagem das mãos frequentemente é um importante meio de prevenção de doenças, e além do mais, a maioria dos participantes realiza a higienização das frutas por meio da lavagem com vinagre 50\%, seguidos de lavagem com água corrente $40 \%$ e somente $10 \%$ cozinha esses alimentos no vapor, e por conta disso, os alimentos tem sido um meio importante de exposição as enteropasitoses, pois o consumo de alimentos frescos tende a aumentar os riscos de contaminação por parasitos intestinais. Por fim, espera-se que este trabalho possa contribuir com os indicadores de saúde do município, estimulando uma parceria entre os gestores de saúde e de educação no planejamento e na execução de ações para a capacitação dos profissionais e aplicação de recursos financeiros que tragam benefícios à saúde dos manipuladores de alimentos, como oferecer melhores condições sanitárias, aumentar a fiscalização da vigilância sanitária nas escolas e verificar se o local é adequado para manipulação de alimentos, buscando diminuir o índice de contaminação e disseminação de enteroparasitoses.

\section{REFERÊNCIAS}

ANVISA, Guia Ilustrado. Cartilha sobre Boas Práticas para Serviço e Alimentação. 2004.

BARROS, D. M. et al. Alimentos contaminados por enteroparasitas: uma questão de saúde pública. Braz J Health Rev [Internet], v. 2, n. 1, p. 277-89, 2019.

BIOLCHI, LC, et al. Enteroparasitos e comensais em estudantes entre 7 e 14 anos em áreas rurais e urbanas do município de CAMPOS NOVOS, Oeste de Santa Catarina, Brasil. Revista de Patologia Tropical/Journal of Tropical Pathology, v. 44, n. 3, p. 337-342, 2015.

BRASIL. Resolução RDC n 216, de 15 de setembro de 2004. Dispõe sobre regulamento técnico de boas práticas para serviços de alimentação. Diário Oficial da União, 2004. Disponível em: < https://bvsms.saude.gov.br/bvs/saudelegis/anvisa/2004/res0216_15_09_2004.html>.

CAMELLO, JT, et al. Prevalência de parasitoses intestinais e condições de saneamento básico das moradias de escolares da zona urbana de Caxias do Sul, Rio Grande do Sul. Scientia Medica, v. 26, n. 1, p. 1-6, 2016. 
CARDOSO, RCV, et al. Programa nacional de alimentação escolar: há segurança na produção de alimentos em escolas de Salvador (Bahia). 2010.

CASTRO, IRR, de et al. Vigilância de fatores de risco para doenças não transmissíveis entre adolescentes: a experiência da cidade do Rio de Janeiro, Brasil. Cadernos de Saúde Pública, v. 24, p. 2279-2288, 2008.

CRESWELL, John W. Projeto de pesquisa: Métodos qualitativo, quantivativo e misto. 3. ed. Porto Alegre: Artmed, 2010.

DE CASTRO, FT; BARBOSA, CG; TABAI, KC. Perfil dos manipuladores de alimentos e a ótica desses profissionais sobre alimento seguro no Rio de Janeiro (RJ). Oikos: Família e Sociedade em Debate, v. 22, n. 1, p. 153-170, 2011.

GENUINO, IP, et al. Ocorrência de enteroparasitos em manipuladores de alimentos das cantinas da Universidade Federal da Paraíba/Campus I. 2015.

GREGÓRIO DS, et al. Estudo da contaminação por parasitas em hortaliças da região leste de São Paulo • São Paulo. Science in Health 3(2): 96-103; maio-ago 2012

JÚNIOR, AFC, et al. Riscos infecciosos no ambiente escolar: relato de experiência com escolares através de metodologia ativa. Saúde \& Transformação Social/Health \& Social Change, v. 8, n. 2, p. 128-134, 2017.

LEÃO, RC, et al. Ocorrência de enteroparasitos e coliformes termotolerantes nas mãos de manipuladores de alimentos de um hospital de ensino. Cadernos Saúde Coletiva, v. 26, n. 2, p. 211-215, 2018.

LIMA-COSTA, MF; BARRETO, SM. Tipos de estudos epidemiológicos: conceitos básicos e aplicações na área do envelhecimento. Epidemiologia e serviços de saúde, v. 12, n. 4, p. 189-201, 2003.

LOPES, MO, et al. Prevalência de helmintíases em manipuladores de alimentos de unidades de alimentação e nutrição escolar públicas de Parnaíba, PI. 2016. Tese de Doutorado.

MATI, VLT; PINTO, JH; DE MELO, AL. Levantamento de parasitos intestinais nas áreas urbana e rural de Itambé do Mato Dentro, Minas Gerais, Brasil. Revista de Patologia Tropical/Journal of Tropical Pathology, v. 40, n. 1, p. 92-100, 2011.

MELO, Zózima Fernades Matos de et al. Complicações da ascaridíase em crianças: uma revisão literária. 2018. 
RODRIGUES, William Costa et al. Metodologia científica. Faetec/IST. Paracambi, p. 01-20, 2007.

SANTOS, YKA, et al. PREVALÊNCIA DE ENTEROPARASITOS EM MANIPULADORES DE ALIMENTOS DE CUITÉ, PARAÍBA, BRASIL. SaBios-Revista de Saúde e Biologia, v. 13, n. 1, p. 21-31, 2018.

SILVA, TO, et al. Enteroparasitos em Crianças de Creches da Cidade de João Pessoa-PB. Revista Cereus, v. 10, n. 1, p. 29-38, 2018. 


\section{Capítulo 8}

O conhecimento dos enfermeiros sobre as políticas públicas existentes especificas do setor saúde em relação a violência contra a mulher

Thays Gouveia Miranda Dos Reis

Lilian Natália Ferreira de Lima

Luysa dos Santos Sanches

Luciana do Socorro Lima da Silva

Artur de Souza Veras
Raquel Machado Borges

Halan Heverton dos Santos Nobre

Patrícia dos Santos Silva Queiroz.

Dennis Gonçalves Novais

Cristiana Maria de Araújo Soares Gomes

Resumo: Verificar o conhecimento dos enfermeiros sobre os tipos de violências contra a mulher e as políticas públicas existentes especificas do setor saúde em relação a violência. Trata-se de uma pesquisa de caráter exploratório e de abordagem qualitativa, tendo como instrumento de coleta de dados um questionário, aplicado as 09 enfermeiras que atuam nas UBS do município de Araguatins, no Estado do Tocantins. A amostra averiguou-se satisfatória em relação ao grau de conhecimento do profissional enfermeiro em relação aos tipos de violências contra a mulher, pois mostraram ter informações sobre o assunto, mas em contrapartida, quanto ao conhecimento das políticas públicas mostraram-se limitados. A atuação das enfermeiras no atendimento de mulheres em situação de violência, fazem-se necessárias melhorias, pois existem dificuldades oriundas dos serviços de assistência, tais como os tabus presentes na sociedade que dificulta o alcance das mulheres visto que tal situação é um problema enraizado que deve ser resolvido através de ações em conjunto de todos os setores, para que assim se desenvolva um plano de cuidado integral e eficaz.

Palavras-chave: Violência de Gênero, Enfermeiro, Assistência. 


\section{INTRODUÇÃO}

A violência é definida como o uso intencional da força ou poder que pode ser real ou por meio de ameaças voltadas a si próprio, contra outras pessoas, grupos ou comunidades, visto que, apresenta como consequências lesões, morte, dano psicológico, deficiência de desenvolvimento ou privação (KRUG et al., 2002). Assim, a violência de gênero fundamenta-se na relação entre homem e mulher, pois ao longo dos anos vem sendo construída socialmente mediante o princípio que o homem é o ativo e deve-se manter no meio público e enquanto a mulher deve manter-se no meio privado (BOURDIEU, 2012). Dessa forma, tal conceito construído socialmente, leva o homem a acreditar na dominação masculina de seus lares e de suas esposas e por isso recorrem à violência.

Nesse sentido, segundo os dados do monitor da violência do grupo do núcleo de pesquisa da USP (2019), mostra que no Brasil a cada duas horas uma mulher morre vítima de violência doméstica e a cada hora dez mulheres são vítimas de violência. Nesse aspecto, o Poder Judiciário do Tocantins, apresenta dados que indicam um crescimento da violência contra mulheres e crianças nos anos de 2018 e 2019, ao mostrar que são 2.500 mil pessoas condenadas por violência doméstica e feminicídio, e mais 6.500 mil aguardam julgamento. Sendo assim, pode-se dizer então que foram 9.000 mil mulheres e crianças que foram abusadas, violentadas ou mortas nesse período (TV ANHANGUERA, 2019). Por fim, a violência contra as mulheres fere os direitos humanos, pois afeta psicologicamente, fisicamente e violando seus direitos. Posto isso, a estratégia de Saúde da família (ESF) é um dos setores de saúde que visa atender as mulheres em situação de violência a partir do reconhecimento dos casos confirmados e suspeitos. Nesse sentido, o Programa de Assistência Integral à Saúde da Mulher (BRASIL. PAISM, 2004) estabelece ações que oportunizam abordar a violência juntamente com outras demandas da mulher, tornando-se parte da prática assistencial.

Portanto, o profissional enfermeiro é o primeiro a atender as vítimas, devendo prestar o cuidado e assistência aos danos físicos e angústias, vergonha, sentimentos de humilhação, medos e receios sempre dando apoio, suporte, confiança e acolhimento promovendo a construção da relação de confiança e compromisso dos pacientes com as equipes e os serviços (MORAES, 2012). Sendo assim, as vítimas de violência devem receber assistência focada no tratamento dos impactos da agressão, principalmente referente às lesões físicas e psicológicas (SILVA, 2013). Assim, o objetivo desse artigo e 
verificar o conhecimento dos enfermeiros sobre os tipos de violências contra a mulher e as políticas públicas existentes especificas do setor saúde em relação a violência.

\section{MÉTODOS}

A metodologia do estudo trata-se de uma pesquisa de cunho exploratória, de abordagem qualitativa. Assim, de acordo com Gil (1999) diz que a pesquisa exploratória é desenvolvida no sentido de proporcionar uma visão geral acerca de determinado fato, e além disso, consiste no aprofundamento de conceitos preliminares sobre determinada temática não contemplada de modo satisfatório anteriormente. Portanto, contribui para o esclarecimento de questões superficialmente abordadas sobre o tema. Dessa maneira, conforme Richardson (1999) afirma que os estudos que empregam uma metodologia qualitativa podem descrever a complexidade de determinado problema, analisar a interação de certas variáveis, compreender e classificar processos dinâmicos vividos por grupos sociais, sendo assim, pode contribuir no processo de mudança de determinado grupo e possibilitar, em maior nível de profundidade, o entendimento das particularidades do comportamento dos indivíduos.

Nesse aspecto, a pesquisa foi realizada nas Unidades Básicas de Saúde no município de Araguatins, no estado do Tocantins, Brasil e a população estudada foram os profissionais de enfermagem das Unidades Básicas de Saúde da Família - UBS do município de Araguatins - T0, pois foi feita a busca ativa de 17 profissionais de enfermagem, que se encaixaram nos critérios de inclusão desta pesquisa, por meio da aplicação de um questionário, porém das 17 enfermeiras atuantes no município no momento da pesquisa apenas 09 enfermeiras aceitaram participar do estudo. Assim, os critérios de seleção da pesquisa incluem o critério de inclusão que são: aceitar participar do estudo; atuar nas unidades de Estratégia Saúde da Família do município de Araguatins; e estar no desempenho das atividades profissionais durante a coleta de dados, e o critério de exclusão estar de acordo com profissionais de férias e/ou com licença médica; e os profissionais que não aceitarem participar da pesquisa.

Desse modo, os procedimentos foram adotados o ciclo de pesquisa de Minayo (1994), que se compõe de três momentos: fase exploratória da pesquisa, trabalho de campo e tratamento do material. Nesse sentido, na análise o pesquisador teve como intuito de organizar e sumariar os dados de tal forma que possibilitem o fornecimento 
de respostas ao problema proposto para investigação, visto que, durante a interpretação procurou-se o sentido mais amplo das respostas, para que assim, possa ser feito mediante sua ligação a outros conhecimentos anteriormente obtidos (GIL, 1999, p. 168). Assim, com base nisso foi construído um banco de dados com os resultados obtidos e feitas comparações analíticas das respostas através de uma plataforma para pesquisa qualitativa.

Portanto, a pesquisa respeita a resolução 466/12 onde foi instituída a Comissão Nacional de Ética em Pesquisa (CONEP) que é uma comissão do Conselho Nacional de Saúde (CNS), criada com a função de implementar normas e diretrizes regulamentadoras de pesquisas envolvendo seres humanos. Dessa forma, a resolução propõe que toda pesquisa envolvendo seres humanos direta ou indiretamente deverá ser submetida à apreciação de um Comitê de Ética em Pesquisa. Sendo assim, foi utilizado o Termo de Consentimento Livre e Esclarecido (TCLE) que é um documento público específico para cada pesquisa e a responsabilidade do pesquisador respeitar e manter a ética em todo o desenvolvimento do trabalho, importante ressaltar que todas as informações pessoais foram mantidas em segredo, respeitando as participantes o máximo para que nenhum dos envolvidos na pesquisa sofresse qualquer tipo de dano. Por fim, o presente estudo foi realizado mediante o parecer favorável do Comitê de Ética em Pesquisa da Universidade Estadual do Tocantins, sob parecer número 4.000.003, na data 30/04/2020, uma vez que, respeitando a resolução 466/12 que incorpora, sob a ótica do indivíduo e das coletividades, referenciais da bioética, como, autonomia, não maleficência, beneficência, justiça e equidade, dentre outros, e visa a assegurar os direitos e deveres que dizem respeito aos participantes da pesquisa (BRASIL, 2012) onde foi utilizando o Termo de Consentimento Livre e Esclarecido (TCLE), pois é um documento público específico para cada pesquisa onde constam todas as informações imprescindíveis sobre a pesquisa e deve ser assinado pelas participantes.

\section{RESULTADOS E DISCUSSÃO}

Os dados examinados e contabilizados serão subdivididos de acordo com os achados do questionário e as variáveis do estudo: Conhecimento quanto aos tipos de violência contra as mulheres e o Conhecimento sobre as políticas públicas. Sendo assim, o primeiro tópico do resultado e discursões centra-se no conhecimento dos enfermeiros 
sobre a conceituação da violência contra as mulheres, em que serão abordados violência doméstica, violência sexual, violência psicológica e violência física. Assim, foi solicitado que os profissionais conceituassem a violência doméstica, destacaram-se as seguintes falas:

E8 - "É um abuso físico ou psicológico. Que na maioria das vezes acontece com mulheres, onde o cônjuge ou ex-cônjuge, namorado ou ex, enfim. Agride para ter algum tipo de controle sobre a parceira. Mais a violência doméstica também pode acontecer com crianças, pessoas idosas e homens."

E9- "É qualquer ação que lhe cause danos como morte, lesão, sofrimento físico, sexual ou psicológico e dano moral".

Desse modo, nota-se que as participantes conceituaram a violência doméstica de forma similar como é definida na lei Maria da penha, onde configura-se violência doméstica como toda ação ou omissão que cause a mulher morte, lesão, sofrimento físico, sexual, psicológico e dano moral ou patrimonial, praticado no âmbito doméstico ou de qualquer relacionamento íntimo atual ou encerrado (BRASIL, 2006). Nesse sentido, segundo o estudo de Silva e Ribeiro (2020) realizado com enfermeiras atuantes na atenção primaria de um município apontam que a maioria das profissionais conceituaram de forma correta os diversos tipos de violência, destacando-se a doméstica, física e psicológica, violência verbal, moral, sexual, o assédio, privação dos direitos da mulher, desrespeito e a desigualdade salarial entre gêneros.

Nesse sentido, a violência sexual, entendida como qualquer conduta que a constranja a presenciar, a manter ou a participar de relação sexual não desejada, mediante intimidação, ameaça, coação ou uso da força (BRASIL, 2006). Sendo assim, no decorrer dos resultados, na segunda pergunta presente no questionário questionava as profissionais sobre a violência sexual, as participantes responderam da seguinte forma: 
E2 - "É aquela em que a parceira não aceita e é obrigada ou seja (estuprada)".

E5 - "Ato indesejado ou tentativa, relações sexuais não consentidas, com repulsão, força física ou ameaças".

E6 - "Qualquer ato sexual indesejado ou tentativa sexual indesejada, seja com toques íntimos não desejados, comentários ou piadas. A pessoa ser forçada a toques em órgãos genitais e via oral, ou seja, pode ocorrer um processo de manipulação onde a pessoa é forçada a cometer ato sexual".

Dessa maneira, de acordo com o estudo de Souza e Oliveira (2016) a violência sexual é um problema de saúde pública, categorizado como uma séria violação dos direitos humanos, com inúmeros impactos na sociedade e qualidade de vida dos indivíduos, e além disso, em um estudo realizado por Martins et., al (2018) no Rio Grande de Sul com profissionais de saúde foi achado os seguintes dados com a relação ao conhecimento sobre a violência, visto que mais de $80 \%$ dos profissionais demonstraram conhecer o conceito e com relação à violência sexual por parceiro íntimo $100 \%$ dos profissionais tiveram respostas assertivas.

Nessa perspectiva, em resposta ao feedback realizado com as participantes foi possível elucidar um ponto importante como o relato das integrantes quando indagados a respeito da seguinte questão: "O que você entende por violência psicológica", logo em seguida é possível constatar a narrativa na integra:

E1 - "Quando a mulher sofre ameaças, isolamentos, perseguições, constrangimentos, humilhação".

E8- "São agressão que causem danos emocionais, que podem desencadear diversos tipos de doenças, como depressão, distúrbios nervosos, transtornos psicológicos e é uma das agressões mais difíceis de identificar pois os danos não são físicos. Essa violência pode ser dada através de ameaças, constrangimentos, humilhações, chantagens, etc".

A violência psicológica é entendida como qualquer conduta que lhe cause danos emocionais e diminuição da autoestima ou que lhe prejudique e perturbe (BRASIL, 2018). Sendo assim, as participantes E1 e E8 citam formas que ocorrem esse tipo de violência como ameaças, constrangimentos, humilhação, chantagens e perseguições, ainda ressaltam que essas ações podem causar danos emocionais permanentes nas 
vítimas como depressão. Assim, a participante E3 diz que a maioria das mulheres que passam por outras formas de violência, inicialmente ocorre a violência psicológica e após vem a violência física e outras formas. Nesse sentido, segundo Xavier et al. (2016) a violência psicológica é a mais difícil de ser identificada, visto que os sinais são silenciosos e de difícil percepção, além de ser um pressuposto para diversos tipos de violência, e suas consequências são graves, podendo levar a vítima à depressão profunda e suicídio. Portanto, é essencial que todos os profissionais estejam cientes da existência da violência psicológica, de como reconhecer e das consequências desta violência, para que seja mais abordado, colocando um fim ao tabu que existe quando se trata de cuidar do emocional, e que possam cuidar das pacientes de forma integral promovendo a saúde de todas, pois quando identificado à violência psicológica no início pode evitar que desenvolva as outras formas.

Nesse aspecto, segundo o sistema de informações de agravos de notificação, a violência física foi a mais recorrente com 50,5\%, pois para entender como está o conhecimento das participantes com relação a violência física e consequentemente a assistência, pedimos para que a conceituassem, destacando as seguintes falas entre elas:

E3 - "Violência física é quando se tem agressão física, por objetos como: armas de fogo, armas brancas entre outros objetos que envolva o corpo físico. Onde também acaba tendo também a violência psicológica pois os dois andam lado a lado".

E4 - "Utilização da força física contra alguém".

E6 - "Através de maus tratos físico ou violência física acometido por atos violentos de forma intencional e não acidental provocando lesão, dor $e$ sofrimento que muitas vezes as marcas evidenciam no corpo".

A violência física de fato é entendida como qualquer conduta que ofenda sua integridade ou saúde corporal, mediante uso de força física, objetos e/ou armas (BRASIL, 2006). Assim, as participantes em sua totalidade concordaram que a violência física é um ato violento intencional que afeta o indivíduo causando danos à saúde, fazendo-se necessário assistência à saúde. Desse modo, um estudo realizado por Freitas et al. (2017), afirmam que na maioria dos casos relacionados a violência, os enfermeiros têm dificuldades em identificar se a vítima não referir a queixa explicitamente, porém quando se trata da violência física os profissionais apresentam mais facilidade tanto em 
conceituar a mesma quanto na identificação, pois tal estudo vai de encontro com os dados observados na pesquisa de SILVA et al (2018) ao afirmar que a violência física é a mais comumente notificada pelo fato de ser mais perceptível e consequentemente identificada com mais facilidade.

Diante disso, para finalizar os resultados da pesquisa, no segundo tópico foi investigado sobre o conhecimento das profissionais frente as políticas públicas, leis e protocolos de atendimento, obtendo os seguintes resultados:

E4 - “Sim. Lei Maria da Penha. Lei no 13931 de 10/12/19”.

E8 - “Sim. Lei Maria da Penha. Lei do feminicídio, entre outras.”

E3 - "Conhecer até conheço, porém no momento não lembro muito de cabeça quais são elas".

E9 - "Não conheço".

Portanto, no Brasil existem legislações e portarias de enfretamento a violência que devem garantir a defesa dos direitos, visto que, vale destacar as mais conhecidas que são: Lei Maria da Penha- 11.340/2006, Lei do Feminicídio- 13.104/2015, Lei da violência doméstica e familiar contra a mulher- 9.099/95. Partindo para os protocolos de atendimento na área da saúde, temos a Política Nacional de Atendimento Integral a Saúde da Mulher (PNAISM), Política Nacional de Enfrentamento à Violência e a Rede Especializada de Atendimento à Mulher, importante ressaltar que cada estado e município também deve ter um protocolo especifico e padrão para atendimento. Sendo assim, nota-se nos achados dois perfis distintos, participantes que referem conhecer a Lei Maria da Penha e as relatam não conhecer. Uma pesquisa realizada por Batista et al. (2017) apontou que a maioria dos participantes "já ouviram falar" sobre as leis e normas, porém nunca foram capacitadas sobre as mesmas durante ou após a graduação, as mais citadas por eles foram a Lei Maria da penha e o PAISM. Nessa perspectiva, de acordo com o citado acima podemos observar que o conhecimento das participantes mediante as legislações e portarias de enfretamento a violência é bem precário, pois tal situação pode ser confirmada com o estudo de Acosta et al. (2017), visto que ressaltou em seu estudo que a maior parte das participantes tem conhecimento limitado sobre as 
competências legais e não ter recebido treinamento especifico e nem informadas sobre as legislações, podemos observar uma situação similar no presente estudo.

\section{CONSIDERAÇÕES FINAIS}

Portanto, verifica-se que, no decorrer do artigo foi observado as dificuldades sentidas pelas profissionais frente o atendimento de casos de violência, percebeu-se certa dificuldade em estabelecer uma relação de confiança com as mulheres e assim uma recusa por parte delas em relatar a violência sofrida e tal situação dificulta-se o processo para a prestação adequada da assistência. Sendo assim, é fundamental a assistência de enfermagem e todos os profissionais sejam capacitados para a identificação da violência, assim como para o manejo dessas situações, para que assim, possa ser desenvolvido uma melhor relação com as vítimas e um protocolo de atendimento multiprofissional eficaz.

\section{REFERÊNCIAS}

ACOSTA DF, et al. "Aspectos éticos e legais no cuidado de enfermagem às vítimas de violência doméstica”. Texto \& Contexto Enfermagem, v. 26, n. 3, p. 1-9, 2017.

BATISTA AC, et al. A Sistematização da Assistência de Enfermagem no atendimento a mulheres vítimas de violência. In: Congresso Internacional de Enfermagem. 2017.

BOURDIEU P. "A dominação masculina"; tradução Maria Helena Kuhner- 9o edição - Rio de Janeiro: Bertrand. Brasil. 160 p. 2010.

BRASIL. Lei ${ }^{\circ} 11.340$ de 07 de Agosto de 2006. Lei Maria da Penha: cria mecanismos para coibir a violência doméstica e familiar contra a mulher... Diário Oficial da União. Brasília, DF, 08 ago. 2006. Disponível em: < http://www.planalto.gov.br/ccivil_03/_ato2004-2006/2006/lei/l11340.htm>. Acessado em: 11 de Novembro de 2019.

BRASIL. Lei n 13.772 de 19 de Dezembro de 2018. Altera a Lei Maria da Penha no conceito de violência psicológica. Diário Oficial da União. Brasília, DF, 19 de Dezembro de 2018. Disponível em: < http://www.planalto.gov.br/ccivil_03/_ato20152018/2018/lei/L13772.htm>. Disponível em: < http://www.planalto.gov.br/ccivil_03/_ato2015-2018/2018/lei/L13772.htm >. Acessado em: 11 de Novembro de 2019.

BRASIL. Decretos e Leis. Lei no 11.340, de 7 de agosto de 2006. Cria mecanismos para coibir a violência doméstica e familiar contra a mulher, nos termos do § 80 do art. 226 da Constituição Federal, da Convenção sobre a Eliminação de Todas as Formas de 
Discriminação contra as Mulheres e da Convenção Interamericana para Prevenir, Punir e Erradicar a Violência contra a Mulher; dispõe sobre a criação dos Juizados de Violência Doméstica e Familiar contra a Mulher; altera o Código de Processo Penal, o Código Penal e a Lei de Execução Penal; e dá outras providências. [da República Federativa do Brasil], Brasília, 08 ago. 2006. Disponível em: < http://www.planalto.gov.br/ccivil_03/_ato20042006/2006/lei/l11340.htm\#: :text=Cri a\%20mecanismos\%20para\%20coibir\%20a,Viol\%C3\%AAncia\%20contra\%20a\%20Mul her\%3B\%20disp\%C3\%B5e>. Acessado em: 11 de Novembro de 2019.

BRASIL. Ministério da Saúde. Política nacional de atenção integral à saúde da mulher: princípios e diretrizes. Brasília, DF: Ministério da Saúde, 2004. Disponível em: https://bvsms.saude.gov.br/bvs/publicacoes/politica_nac_atencao_mulher.pdf. Acessado em: 11 de Novembro de 2019.

FREITAS RJM, et al. Atuação dos enfermeiros na identificação e notificação dos casos de violência contra a mulher. HU Revista, Juiz de Fora. 2017; 43(2):91-97.

GIL AC. Métodos e técnicas de pesquisa social. 5.ed. São Paulo: Atlas, 1999.

KRUG EG, et al. (eds.) World report on violence and health. Geneva: World Health Organization, 2002.

MARTINS LCA, et al. Violência de gênero: conhecimento e conduta dos profissionais da estratégia saúdem da família. Revista Gaúcha Enferm [Internet]. 2018 jul 39:e20170030.

MINAYO MCS, SOUZA ER. Violência e saúde como um campo interdisciplinar e de ação coletiva. Hist. cienc. saúde-Manguinhos, Rio de Janeiro, v. 4, n.3, p. 513-531, nov. 1997.

MORAES AF, RIBEIRO L. As políticas de combate à violência contra a mulher no Brasil e a "responsabilização" dos "homens autores de violência". Sexualidad, Salud Sociedad. Revista Latino Americana. Rio Janeiro, n.11, p. 37-58, 2012.

RICHARDSON RJ. Pesquisa social: métodos e técnicas. 3. ed. São Paulo: Atlas,1999.

RIBEIRO TAMBORIL AC, et al. Nursing diagnosis" Deficient Knowledge" in users of combined oral contraceptive. Revista Eletronica de Enfermagem, v. 17, n. 4, 2015.

SANTOS SC, et al. Violência contra a mulher: como os profissionais na Atenção Primária à Saúde estão enfrentando esta realidade? Revista Saúde e Pesquisa, Maringá, v. $11, \quad$ n. $2, \quad$ p.359-368, 2018.

SILVA EB, et al. Violência contra a mulher: limites e potencialidades da prática assistencial. Acta Paul Enferm. 2013; 26(6):608-13. 
SILVA VG, RIBEIRO PM. Violência contra as mulheres na prática de enfermeiras da atenção primária à saúde. Escola Anna Nery, v. 24, n. 4, 2020.

SOUZA MMS, OLIVERA MVP. Violência sexual contra a mulher e o papel do enfermeiro: revisão de literatura. [trabalho de conclusão de curso]. 21f. Universidade Tiradentes, Aracajú-SE, 2016.

TV ANHANGUERA. “Em 15 meses, quase 30 mil mulheres sofreram violência domestica no Tocantins". 2019. Disponível em:

https://g1.globo.com/to/tocantins/noticia/2019/11/25/em- 15-meses-quase-30-milmulheres-sofreram-violencia-domestica-no-tocantins.ghtml; Acesso em: 02/12/2019.

XAVIER LS, et al. Violência contra a mulher: violência psicológica como pressuposto para as outras formas de violência. In: III Foro Latinoamericano de Trabajo Social (La Plata, Argentina, 2016). 2016. 


\section{www.poisson.com.br contato@poisson.com.br}

@editorapoisson 